Article

\title{
Polymorphism and Metallic Behavior in BEDT-TTF Radical Salts with Polycyano Anions
}

\author{
Samia Benmansour ${ }^{1}$, Mathieu Marchivie ${ }^{2,3}$, Smail Triki ${ }^{2}$ and Carlos J. Gómez-García ${ }^{1}$ * \\ 1 Institute of Molecular Science (ICMol), University of Valencia, 46980 Paterna, Valencia, Spain; \\ E-Mail: sam.ben@uv.es \\ 2 European University of Brittany (University of Brest), UMR CNRS 6521, 6 Av. V. Le Gorgeu, \\ C.S. 93837, 29238 Brest, France; E-Mails: mathieu.marchivie@u-bordeaux2.fr (M.M.); \\ Smail.Triki@univ-brest.fr (S.T.) \\ 3 University of Bordeaux, CNRS FRE 3396, 146, rue Léo Saignat, 33076 Bordeaux, France \\ * Author to whom correspondence should be addressed; E-Mail: carlos.gomez@uv.es; \\ Tel.: +34-963544423; Fax: +34-963543723.
}

Received: 27 March 2012; in revised form: 12 April 2012 / Accepted: 13 April 2012 /

Published: 23 April 2012

\begin{abstract}
Up to five different crystalline radical salts have been prepared with the organic donor BEDT-TTF and three different polynitrile anions. With the polynitrile dianion $\operatorname{tcpd}^{2-}\left(=\mathrm{C}\left[\mathrm{C}(\mathrm{CN})_{2}\right]_{3}{ }^{2-}\right)$, two closely related radical salts: $\alpha^{\prime}-(\mathrm{ET})_{4}$ tcpd-THF (1) $\left(\mathrm{THF}=\right.$ tetrahydrofurane) and $\alpha^{\prime}-(\mathrm{ET})_{4} \mathrm{tcpd} \cdot \mathrm{H}_{2} \mathrm{O}$ (2) have been prepared, depending on the solvent used in the synthesis. With the mono-anion tcnoetOH ${ }^{-}$ $\left(=\left[(\mathrm{NC})_{2} \mathrm{CC}\left(\mathrm{OCH}_{2} \mathrm{CH}_{2} \mathrm{OH}\right) \mathrm{C}(\mathrm{CN})_{2}\right]^{-}\right)$two polymorphs with similar physical properties but different crystal packings have been synthesized: $\theta-(\mathrm{ET})_{2}($ tcnoetOH) (3) and $\quad \beta^{\prime \prime}-(\mathrm{ET})_{2}($ tcnoetOH$) \quad$ (4). Finally, with the mono-anion tcnoprOH ${ }^{-}$ $\left(=\left[(\mathrm{NC})_{2} \mathrm{CC}\left(\mathrm{OCH}_{2} \mathrm{CH}_{2} \mathrm{CH}_{2} \mathrm{OH}\right) \mathrm{C}(\mathrm{CN})_{2}\right]^{-}\right)$we have prepared a metallic radical salt: $\beta "$ "-(ET) $)_{2}($ tcnoprOH $)\left(\mathrm{CH}_{2} \mathrm{Cl}_{2} \mathrm{CH}_{3} \mathrm{Cl}\right)_{0.5}$ (5). Salts $\mathbf{1 - 4}$ are semiconductors with high room temperature conductivities and activation energies in the range $0.1-0.5 \mathrm{eV}$, whereas salt 5 is metallic down to $0.4 \mathrm{~K}$ although it does not show any superconducting transition above this temperature.
\end{abstract}

Keywords: bis(ethylenedithio)tetrathiafulvalene; polycyano anions; molecular conductors; synthetic metals 


\section{Introduction}

Since the discovery of metallic conductivity in the charge transfer complex TTF-TCNQ [1] (TTF = tetrathiafulvalene, TCNQ = tetracyanoquinodimethane) and, especially superconductivity in the Bechgard salts [2], the number of charge transfer complexes and radical salts containing TTF and its derivatives has not ceased to increase. Thus, the CCDC database updated in February 2012 shows ca. 2600 different structurally characterized compounds containing TTF or any of its numerous derivatives. Among these, the most common is the organic donor bis(ethylenedithio)tetrathiafulvalene (BEDT-TTF or ET, Scheme 1), with almost 500 different compounds known to date. The main reason for this popularity of ET is the fact that almost one half of the $c a .100$ molecular superconductors prepared to date is based on this donor.

Scheme 1. BEDT-TTF and the polycyano anions used in this work.

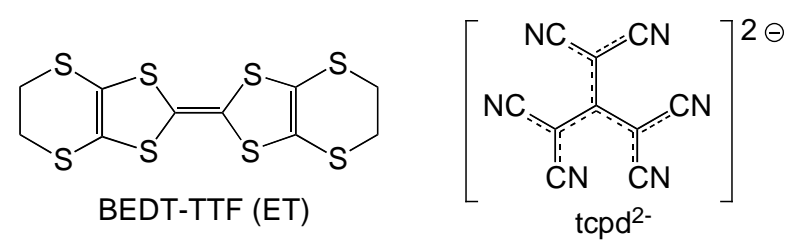<smiles>N#CC(C#N)C(OCCO)C(C#N)C(C#N)C(C#N)C(C#N)C(=O)O</smiles>

The number of anions combined with TTF-type donors is also very large, ranging from simple halides and oxo-anions to paramagnetic metal complexes as $\left[\mathrm{MX}_{4}\right]^{n^{-}}[3-5]$ and $\left[\mathrm{M}\left(\mathrm{C}_{2} \mathrm{O}_{4}\right)_{3}\right]^{3-}[6-11]$ to polyoxometalates with large sizes and charges [12-16] and even extended ferromagnetic layers [17-20].

Among the hundreds of different anions combined with TTF-type donors, the one leading to the highest superconducting transition temperatures is dicyanamide $\left(\left[\mathrm{N}(\mathrm{CN})_{2}\right]^{-}=\mathrm{dca}^{-}\right)$. Thus, the salts

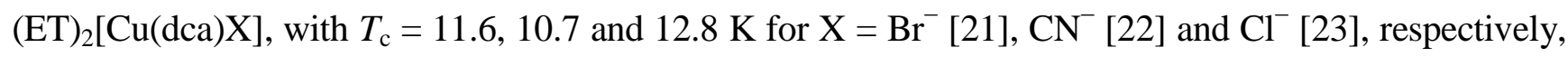
present the highest transition temperatures among all the TTF-type superconductors. However, despite these high critical temperatures and the fact that the first metal with TTF was prepared with TCNQ, that also contains two juxtaposed cyano groups $\left[-\mathrm{C}(\mathrm{CN})_{2}\right]$, the number of anions containing this functional group combined with TTF-type donors is still limited, as clearly shown by Geiser and Schlueter in an excellent review on these and many other anions (Tables 1-3) [24].

Table 1. ET salts with TCNQ derivatives.

\begin{tabular}{llll}
\hline Compound & CCDC code & Anion & Ref. \\
\hline$(\mathrm{ET})\left(\mathrm{Me}_{2}\right.$ TCNQ $)$ & ASAVIZ & $\mathrm{Me}_{2}$ TCNQ & {$[25]$} \\
$(\mathrm{ET})(\mathrm{ClMeTCNQ})$ & ASAVOF & ClMeTCNQ & {$[25]$} \\
$(\mathrm{ET})(\mathrm{FTCNQ})$ & RIQBOI & FTCNQ & {$[26]$} \\
$(\mathrm{ET})\left(\mathrm{F}_{2} \text { TCNQ }\right)_{0.5}(\mathrm{TCNQ})_{0.5}$ & - & FTCNQ/TCNQ & {$[26]$} \\
$(\mathrm{ET})(\mathrm{TCNQ})$ & FAHLEF & TCNQ & {$[27]$} \\
\hline
\end{tabular}


Table 2. ET salts with polycyano anions.

\begin{tabular}{lllc}
\hline Formula & CCDC code & Anion & Ref. \\
\hline$\delta^{\prime}-(\mathrm{ET})_{2}\left[\mathrm{C}(\mathrm{CN})_{3}\right]$ & KADGUR & {$\left[\mathrm{C}(\mathrm{CN})_{3}\right]^{-}$} & {$[28]$} \\
$\alpha^{\prime}-(\mathrm{ET})_{2}(\mathrm{tcpd})$ & - & $\mathrm{tcpd}^{2-}$ & {$[29]$} \\
$\alpha^{\prime}-(\mathrm{ET})_{4}(\mathrm{tcpd}) \cdot \mathrm{THF}$ & - & $\mathrm{tcpd}^{2-}$ & this work \\
$\alpha^{\prime}-(\mathrm{ET})_{4}(\mathrm{tcpd}) \cdot 2 \mathrm{H}_{2} \mathrm{O}$ & - & $\mathrm{tcpd}^{2-}$ & this work \\
$\delta^{\prime}-(\mathrm{ET})_{2}\left[\mathrm{C}_{5}(\mathrm{CN})_{5}\right](\mathrm{TCE})_{x}$ & VERTAN & {$\left[\mathrm{C}_{5}(\mathrm{CN})_{5}\right]^{-}$} & {$[30]$} \\
$\beta^{\prime \prime}-(\mathrm{ET})_{4}\left[\mathrm{C}_{6}(\mathrm{CN})_{8}\right](\mathrm{THF})_{2}$ & QOTHEM & {$\left[\mathrm{C}_{6}(\mathrm{CN})_{8}\right]^{-}$} & {$[31]$} \\
$(\mathrm{ET})\left[\mathrm{C}_{6} \mathrm{~S}_{2}(\mathrm{CN})_{4}\right]$ & GERYOR & {$\left[\mathrm{C}_{6} \mathrm{~S}_{2}(\mathrm{CN})_{4}\right]^{-}$} & {$[32]$} \\
$\beta^{\prime \prime}-(\mathrm{ET})_{2}\left\{\left[(\mathrm{CN})_{2} \mathrm{C}\right]_{2} \mathrm{CO}\left(\mathrm{CH}_{2}\right)_{2} \mathrm{CH}_{3}\right\}$ & - & $\left\{\left[(\mathrm{CN})_{2} \mathrm{C}\right]_{2} \mathrm{CO}\left(\mathrm{CH}_{2}\right)_{2} \mathrm{CH}_{3}\right\}^{-}$ & {$[33]$} \\
$\theta-(\mathrm{ET})_{2}(\mathrm{tcnoetOH})$ & - & $\operatorname{tcnoetOH}^{-}$ & this work \\
$\beta^{\prime \prime}-(\mathrm{ET})_{2}(\mathrm{tcnoetOH})$ & - & $\operatorname{tcnotOH}^{-}$ & this work \\
$\beta^{\prime \prime}-(\mathrm{ET})_{2}(\mathrm{tcnoprO})\left(\mathrm{CH}_{2} \mathrm{ClCHCl}_{2}\right)_{0.5}$ & - & $\operatorname{tcnoprOH}^{-}$ & this work \\
$(\mathrm{ET})\left\{\mathrm{N}\left[\mathrm{C}_{2}(\mathrm{CN})_{3}\right]_{2}\right\}$ & - & $\left\{\mathrm{N}_{2}\left[\mathrm{C}_{2}\left(\mathrm{CN}_{3}\right]_{2}\right\}^{-}\right.$ & {$[34]$} \\
\hline
\end{tabular}

Table 3. ET salts with the dicyanamide (dca) anion.

\begin{tabular}{llll}
\hline Formula & CCDC code & Anion & Ref. \\
\hline$(\text { ET })_{2}(\mathrm{dca}) \cdot 2 \mathrm{H}_{2} \mathrm{O}$ & SOXWUY & $\mathrm{dca}^{-}$ & {$[35]$} \\
$\delta^{\prime}-(\mathrm{ET})_{2}(\mathrm{dca})$ & - & $\mathrm{dca}^{-}$ & {$[36]$} \\
$(\mathrm{ET})(\mathrm{dca}) \cdot \mathrm{H}_{2} \mathrm{O}$ & - & $\mathrm{dca}^{-}$ & {$[24]$} \\
$(\mathrm{ET})_{2}[\mathrm{Cu}(\mathrm{dca}) \mathrm{Cl}]$ & WEHJAV & {$[\mathrm{Cu}(\mathrm{dca}) \mathrm{Cl}]^{-}$} & {$[23]$} \\
$(\mathrm{ET})_{2}[\mathrm{Cu}(\mathrm{dca}) \mathrm{Br}]$ & JESDUG & {$[\mathrm{Cu}(\mathrm{dca}) \mathrm{Br}]^{-}$} & {$[21]$} \\
$(\mathrm{ET})_{2}[\mathrm{Cu}(\mathrm{dca}) \mathrm{CN}]$ & VORNAR & {$[\mathrm{Cu}(\mathrm{dca})(\mathrm{CN})]^{-}$} & {$[22]$} \\
$(\mathrm{ET})_{2}\left[\mathrm{Mn}(\mathrm{dca})_{3}\right]$ & - & {$\left[\mathrm{Mn}(\mathrm{dca})_{3}\right]^{-}$} & {$[37]$} \\
$(\mathrm{ET})_{2}\left[\mathrm{CuMn}(\mathrm{dca})_{4}\right]$ & QIXSOG & {$\left[\mathrm{MnCu}(\mathrm{dca})_{4}\right]^{-}$} & {$[38]$} \\
\hline
\end{tabular}

If we limit the search to ET, there are only five salts prepared with TCNQ and its derivatives (Table 1): (ET)(Me 2 TCNQ), (ET)(ClMeTCNQ) [25], (ET)(F-TCNQ), (ET)(F F $_{2}$ TCNQ) ${ }_{0.5}(\mathrm{TCNQ})_{0.5}$ [26], and (ET)(TCNQ) [27], seven salts with polycyano anions (Table 2): $(\mathrm{ET})_{2}\left[\mathrm{C}(\mathrm{CN})_{3}\right]$ [28], $(\mathrm{ET})_{2}\left[\mathrm{C}_{4}(\mathrm{CN})_{6}\right]$ [29], $(\mathrm{ET})_{2}\left[\mathrm{C}_{5}(\mathrm{CN})_{5}\right](\mathrm{TCE})_{x}[30],(\mathrm{ET})_{4}\left[\mathrm{C}_{6}(\mathrm{CN})_{8}\right](\mathrm{THF})_{2}[31],(\mathrm{ET})\left[\mathrm{C}_{6} \mathrm{~S}_{2}\left(\mathrm{C}(\mathrm{CN})_{2}\right)_{2}\right]$ [32], (ET) $)_{2}$ (tcnopr) [33] (tcnopr $\left.{ }^{-}=\left[(\mathrm{NC})_{2} \mathrm{CC}\left(\mathrm{OCH}_{2} \mathrm{CH}_{2} \mathrm{CH}_{3}\right) \mathrm{C}(\mathrm{CN})_{2}\right]^{-}\right)$and $(\mathrm{ET})\left\{\mathrm{N}\left[\mathrm{C}_{2}(\mathrm{CN})_{3}\right]_{2}\right\}$ [34], three phases with $\mathrm{dca}^{-}$(Table 3) $[24,35,36]$ and five other compounds involving the $\mathrm{dca}^{-}$anion and transition metal ions: $(\mathrm{ET})_{2}[\mathrm{Cu}(\mathrm{dca})(\mathrm{CN})]$ [22], $(\mathrm{ET})_{2}[\mathrm{Cu}(\mathrm{dca}) \mathrm{Cl}]$ [23], (ET) $)_{2}[\mathrm{Cu}(\mathrm{dca}) \mathrm{Br}]$ [21], $(\mathrm{ET})_{2} \mathrm{Mn}(\mathrm{dca})_{3}$ [37] and $(\mathrm{ET})_{2}\left[\mathrm{CuMn}(\mathrm{dca})_{4}\right][21,38]$. A possible reason explaining this lack of radical salts with this kind of anions may be the difficulty of obtaining single crystals of these compounds given the rigidity of the cyano groups and the lack of planarity of the $-\mathrm{X}(\mathrm{CN})_{2}$ groups in the corresponding anions (except in the $\mathrm{dca}^{-}$anion, which, accordingly, is the most successful one). Although ET is the most used donor with this kind of anions, other donors such as bis(ethylenediseleno)tetrathiafulvalene (BETS-TTF) [39], bis(ethylenedioxy)tetrathiafulvalene (BEDO-TTF) [40,41], TTF [42], and tetrathiotetracene (TTT) [43] have been used with these polycyano anions.

Besides their use in the aforementioned radical salts, polycyano anions have also been extensively used as original ligands with several transition metal ions [44] to yield coordination compounds with dimensionalities ranging from discrete clusters [45] to extended 1D [46], 2D [47] and 3D [48] structures. The ability of these polycyano anions to form extended coordination polymers is mainly due to the 
rigidity of their two or more $-\mathrm{C}(\mathrm{CN})_{2}$ groups, that avoids a chelating coordination mode and facilitates different bridging modes, including the unusual formation of linkage isomers [49,50]. Furthermore, the presence of cyano groups able to create appropriate ligand fields has also been exploited to prepare spin crossover complexes with transition temperatures above room temperature [51,52].

Here we report the synthesis, structural and physical characterization of five novel molecular conductors prepared with the organic donor ET and three different polycyano anions: tcpd $^{2-}$, tcnoetOH ${ }^{-}$and tcnoprOH ${ }^{-}$(Scheme 1). The tcpd ${ }^{2-}$ dianion gives rise to two salts with the same formula but with different solvate molecules: $\alpha^{\prime}-(\mathrm{ET})_{4}(\mathrm{tcpd}) \cdot \mathrm{THF}(\mathbf{1})$ and $\alpha^{\prime}-(\mathrm{ET})_{4}(\mathrm{tcpd}) \cdot 2 \mathrm{H}_{2} \mathrm{O}(\mathbf{2})$. The tcnoetOH ${ }^{-}$anion yields two different polymorphs formulated as $\theta-(\mathrm{ET})_{2}(\mathrm{tcnoetOH})$ (3) and $\beta "$-(ET) $)_{2}(\mathrm{tcnoetOH})(4)$. Finally, with the tcnoprOH ${ }^{-}$anion we have obtained a metallic salt formulated as: $\beta "-(\mathrm{ET})_{2}(\mathrm{tcnoprOH})\left(\mathrm{CHCl}_{2} \mathrm{CH}_{2} \mathrm{Cl}\right)_{0.5}(\mathbf{5})$.

\section{Results and Discussion}

\subsection{Synthesis}

All the radical salts have been prepared with the electrocrystallization method using the $\mathrm{K}^{+}$ salts of the corresponding polycyano anions: $\mathrm{K}_{2}(\mathrm{tcpd}) \cdot 2 \mathrm{H}_{2} \mathrm{O}$, KtcnoetOH, and $\mathrm{KtcnoprOH}$, except compound 5, that was prepared using the $\mathrm{Cu}(\mathrm{tcnoprOH})_{2}$ salt. The THF solvate $\alpha^{\prime}-(\mathrm{ET})_{4}(\mathrm{tcpd}) \cdot \mathrm{THF}(\mathbf{1})$ has been obtained as dark brown prisms by using a mixture of THF and $\mathrm{CH}_{2} \mathrm{Cl}_{2}$ whereas the $\mathrm{H}_{2} \mathrm{O}$ solvate $\alpha^{\prime}$-(ET) $)_{4}$ (tcpd) $\cdot 2 \mathrm{H}_{2} \mathrm{O}$ (2) was obtained as black prisms when a $\mathrm{EtOH} / \mathrm{CH}_{2} \mathrm{Cl}_{2} / \mathrm{CHCl}_{2} \mathrm{CH}_{2} \mathrm{Cl}$ mixture is used with two drops of water. In contrast to compounds $\mathbf{1}$ and $\mathbf{2}$, where the synthetic conditions were not exactly the same, compounds $\mathbf{3}$ and $\mathbf{4}$ were obtained simultaneously in the same electrocrystallization cell, using a EtOH/ $\mathrm{CH}_{2} \mathrm{Cl}_{2} / \mathrm{CHCl}_{2} \mathrm{CH}_{2} \mathrm{Cl}$ mixture. They were easily distinguished because the polymorph $\theta-(\mathrm{ET})_{2}(\mathrm{tcnoetOH})(3)$ is obtained as black plate-like crystals whereas the phase $\beta^{\prime \prime}$-(ET) $)_{2}(\mathrm{tcnoetOH})$ (4) crystallizes as long black needles. $\beta "-(\mathrm{ET})_{2}(\mathrm{tcnoprOH})\left(\mathrm{CHCl}_{2} \mathrm{CH}_{2} \mathrm{Cl}\right)_{0.5}$ (5) was obtained as brown shiny prisms with a mixture of $\mathrm{EtOH} / \mathrm{CHCl}_{2} \mathrm{CH}_{2} \mathrm{Cl}$ (see experimental section).

\subsection{Crystal Structures}

\subsubsection{Structures of $\alpha^{\prime}-(\mathrm{ET})_{4}(\mathrm{tcpd}) \cdot \mathrm{THF}(\mathbf{1})$ and $\alpha^{\prime}-(\mathrm{ET})_{4}(\mathrm{tcpd}) \cdot 2 \mathrm{H}_{2} \mathrm{O}(\mathbf{2})$}

Compounds $\mathbf{1}$ and $\mathbf{2}$ are isostructural and crystallize in the monoclinic space group C2/c. Crystal and refinement data are shown in Table 4. The only difference is the presence of a disordered THF molecule in the anionic layer in compound $\mathbf{1}$ and two water molecules in compound $\mathbf{2}$. Both compounds present cationic ET layers alternating along the $c$ axis with layers containing the tcpd ${ }^{2-}$ anions and the solvent molecules (Figure 1).

The ET molecules show the so-called $\alpha^{\prime}$ packing in which the organic donors form chains where all the ET molecular planes are parallel [53]. The difference with other parallel packings is that now the long axes of the ET molecules are not parallel but form a twist angle ( $\omega$, in the range $32-34^{\circ}$ in compounds 1 and 2) with the neighboring molecules in the chain (Figure 1). Besides the twisting, there is a displacement of the center of adjacent ET molecules, noted as D in Figure 1. Note that the so-called $\delta$ and $\delta^{\prime}$ phases are very similar but in these phases the overlap between adjacent ET molecules in the 
chains follows the alternating sequence ...-RA-twisted-... $(\mathrm{RA}=$ ring-over-atom $)$ and ...-RB-twisted-... $\left(\mathrm{RB}=\right.$ ring-over-bond), respectively, whereas in the $\alpha^{\prime}$ phase the overlap is always twisted [53].

Table 4. Crystal data for compounds $\alpha^{\prime}-\mathrm{ET}_{4}(\mathrm{tcpd})(\mathrm{THF})(\mathbf{1})$ and $\alpha^{\prime}-\mathrm{ET}_{4}(\mathrm{tcpd})\left(\mathrm{H}_{2} \mathrm{O}\right)_{2}(\mathbf{2})$.

\begin{tabular}{|c|c|c|}
\hline Compound & 1 & 2 \\
\hline Formula & $\mathrm{C}_{54} \mathrm{H}_{40} \mathrm{~N}_{6} \mathrm{OS}_{32}$ & $\mathrm{C}_{50} \mathrm{H}_{36} \mathrm{~N}_{6} \mathrm{O}_{2} \mathrm{~S}_{32}$ \\
\hline$M$ & 1814.84 & 1778.76 \\
\hline Cryst. Syst. & Monoclinic & Monoclinic \\
\hline Space group & $\mathrm{C} 2 / \mathrm{c}$ & $\mathrm{C} 2 / \mathrm{c}$ \\
\hline$a(\AA)$ & $15.7423(13)$ & $15.5152(13)$ \\
\hline$b(\AA)$ & $13.2947(11)$ & $13.2644(10)$ \\
\hline$c(\AA)$ & $33.810(3)$ & $33.673(2)$ \\
\hline$\beta\left(^{\circ}\right)$ & $96.701(6)$ & $97.443(6)$ \\
\hline$V\left(\AA^{3}\right)$ & 7027.7(10) & $6871.5(9)$ \\
\hline$Z$ & 4 & 4 \\
\hline$T(\mathrm{~K})$ & 293(2) & $170(2)$ \\
\hline$\rho_{\text {calc }}\left(\mathrm{g} \cdot \mathrm{cm}^{-3}\right)$ & 1.708 & 1.719 \\
\hline$\mu\left(\mathrm{cm}^{-1}\right)$ & 9.406 & 10.36 \\
\hline$F(000)$ & 3672 & 3624 \\
\hline Refl. Collec. & 40764 & 16,092 \\
\hline Refl. Uniq. & 5029 & 3379 \\
\hline$R_{\text {int }}$ & 0.0588 & 0.0807 \\
\hline Refl. Obs $I>2 \sigma(I)$ & 2614 & 2051 \\
\hline$N_{\mathrm{v}}$ & 568 & 274 \\
\hline${ }^{\mathrm{a}} R 1$ & 0.0790 & 0.1562 \\
\hline${ }^{\mathrm{b}} w R 2$ & 0.2542 & 0.4738 \\
\hline${ }^{\mathrm{c}}$ GooF & 0.963 & 1.730 \\
\hline$\Delta \rho_{\max }\left(\mathrm{e} \AA^{-3}\right)$ & 0.690 & +2.271 \\
\hline$\Delta \rho_{\min }\left(\mathrm{e} \AA^{-3}\right)$ & -0.409 & -1.359 \\
\hline
\end{tabular}

Figure 1. (a) View of the alternating cationic and anionic layers in compound $\mathbf{1}$ along the $\mathrm{c}$ axis (similar structure for compound 2); (b) View of the ET layer. Dotted lines indicate the S...S contacts shorter than the sum of the van der Waals radii; (c) Side view of the ET chains; (d) View of the overlap between neighboring ET molecules in the chain.

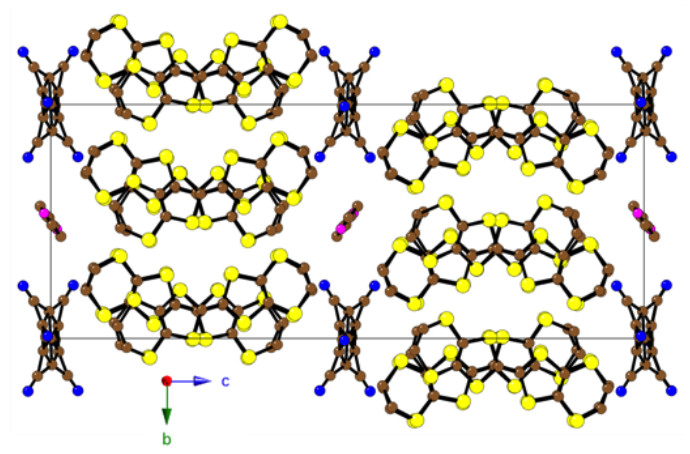

(a)

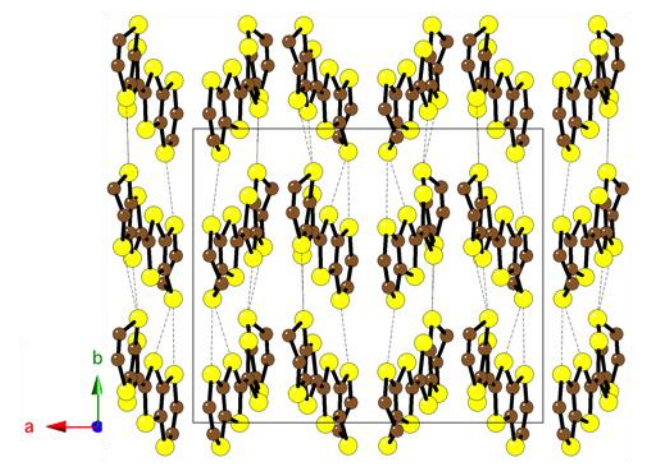

(b) 
Figure 1. Cont.

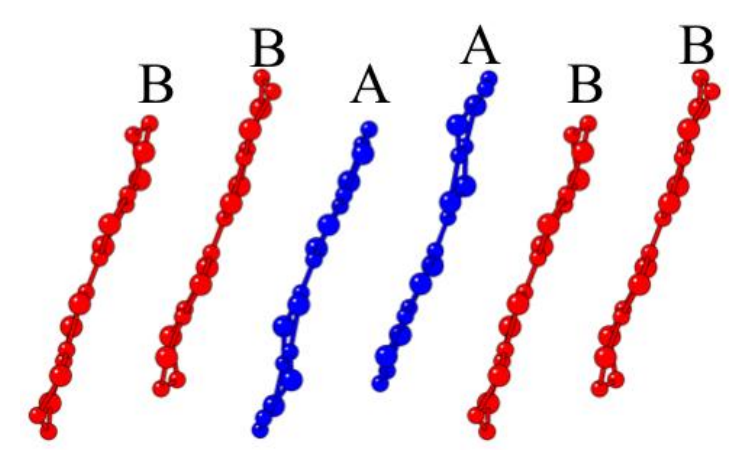

(c)

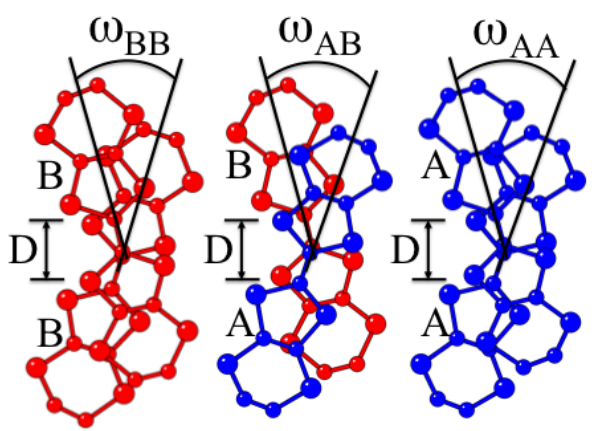

(d)

Since the chains are formed by two crystallographically independent ET molecules (noted as A and $\mathrm{B}$ ) following the sequence ...-AABB-..., there are three different intra-chain overlaps: $\mathrm{A}-\mathrm{A}, \mathrm{A}-\mathrm{B}$ and $\mathrm{B}-\mathrm{B}$, all with similar twisting angles $(\omega)$ and displacements $(D): \omega_{\mathrm{AA}}=34.0^{\circ}, D_{\mathrm{AA}}=1.39 \AA$, $\omega_{\mathrm{AB}}=33.2^{\circ}, D_{\mathrm{AB}}=1.38 \AA, \omega_{\mathrm{BB}}=32.4^{\circ}$ and $D_{\mathrm{BB}}=1.41 \AA$, in compound $\mathbf{1}$ and $\omega_{\mathrm{AA}}=34.0^{\circ}, D_{\mathrm{AA}}=1.39 \AA$, $\omega_{\mathrm{AB}}=32.8^{\circ}, D_{\mathrm{AB}}=1.32 \AA, \omega_{\mathrm{BB}}=32.0^{\circ}$ and $D_{\mathrm{BB}}=1.28 \AA$ in compound 2 (Figure 1).

The two terminal ethylene groups of the A-type ET molecule in compound $\mathbf{1}$ present a boat conformation and are staggered whereas those on the B-type ET molecule present a half-chair conformation and are also staggered. In compound $\mathbf{2}$ the A-type molecule presents a boat conformation in one of the ethylene groups and a half chair in the other whereas the B-type molecules presents a staggered half chair conformation in both ethylene groups.

As observed in other $\alpha^{\prime}$ phases [53], there are many intermolecular S ...S contacts shorter than the sum of the van der Waals radii in both compounds (Table 5). Although the structure of compound 2 is not very precise, the analysis of the bond lengths in the central TTF skeleton of the ET molecules in both compounds [54] suggests an homogeneous charge distribution where both ET molecules bear similar charges, close to +0.5 , giving an overall charge of +2 for the four ET molecules, in agreement with the -2 charge of the anion and the stoichiometry of the salts (4:1).

Table 5. Intermolecular $\mathrm{S} \cdots \mathrm{S}$ distances (in $\AA$ ) shorter than the sum of the van der Waals radii (3.6 ̊) in compounds $\mathbf{1}$ and $\mathbf{2}$.

\begin{tabular}{|c|c|c|c|c|c|}
\hline \multicolumn{2}{|c|}{ Compound 1} & \multicolumn{4}{|c|}{ Compound 2} \\
\hline Atoms & Distance & Atoms & Distance & Atoms & Distance \\
\hline S1‥S10 & $3.524(3)$ & S1A-S3B & $3.59(1)$ & S6A-S1B & $3.43(1)$ \\
\hline $\mathrm{S} 2 \mathrm{~A} \cdots \mathrm{S} 9$ & $3.477(7)$ & S1A-S6B & $3.48(1)$ & S6A-S5B & $3.42(1)$ \\
\hline $\mathrm{S} 2 \mathrm{~A} \cdots \mathrm{S} 12$ & $3.426(7)$ & S3A-S1B & $3.59(1)$ & S7A-S4B & $3.32(1)$ \\
\hline S4 $\cdots S 10$ & $3.527(3)$ & S4A-S7B & $3.55(1)$ & S7A-S8B & $3.38(1)$ \\
\hline S6 $\cdots$ S16 & $3.468(3)$ & S5A-S6B & $3.57(1)$ & S8A-S7B & $3.50(1)$ \\
\hline $\mathrm{S} 7 \cdots \mathrm{S} 16$ & $3.534(3)$ & & & & \\
\hline S8 $\cdots$ S14 & $3.438(3)$ & & & & \\
\hline S8 $\cdots \mathrm{S} 15$ & $3.429(3)$ & & & & \\
\hline
\end{tabular}

The anionic layer (in the $a b$ plane) is formed by tcpd ${ }^{2-}$ anions that appear disordered since they are located on an inversion center on the central carbon atom (C21). This inversion center generates 
two superimposed anions, as clearly shown in Figure 2 and already observed in a Fe(II) chain with $\operatorname{tcpd}^{2-}$ [55]. The solvent molecules (disordered THF in $\mathbf{1}$ and two water molecules in 2 ) are located between the $\operatorname{tcpd}^{2-}$ anions.

Figure 2. View of the statistical disorder of the tcpd ${ }^{2-}$ anion in compound 1 (similar in 2). Symmetry operation: * $=-\mathrm{x},-\mathrm{y},-\mathrm{z}$.
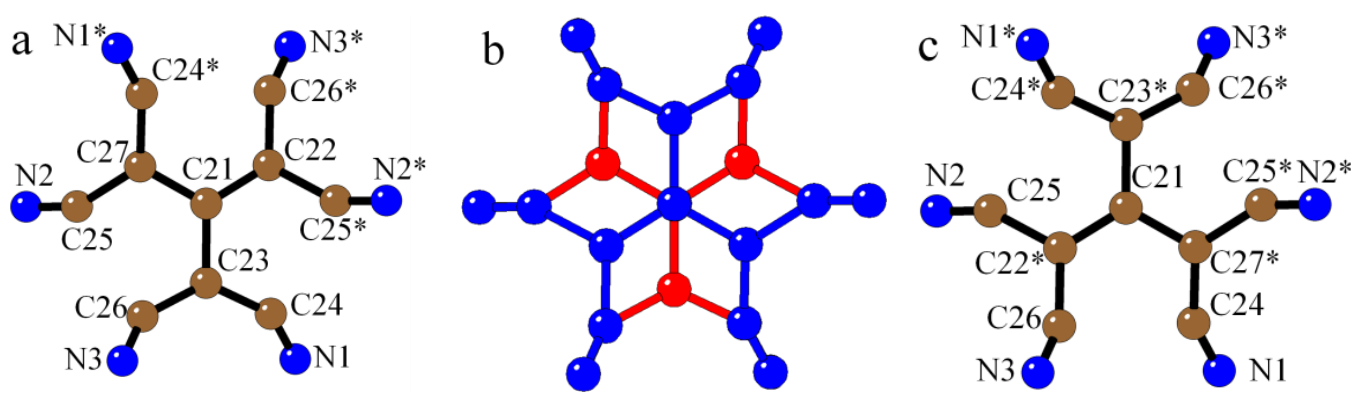

2.2.2. Structures of $\theta-(\mathrm{ET})_{2}(\mathrm{tcnoetOH})(3)$ and $\beta^{\prime \prime}-(\mathrm{ET})_{2}(\mathrm{tcnoetOH})(\mathbf{4})$

Compounds 3 and 4 crystallize in the triclinic space group P-1 but show different ET packings. Crystal and refinement data are shown in Table 6. According to the asymmetric unit the chemical formula of compound 3 should be $\theta-(\mathrm{ET})_{8}(\mathrm{tcnoetOH})_{4}$ (see description below), but the chemical formula $\theta-(\mathrm{ET})_{2}$ (tcnoetOH) was preferred to facilitate its crystal structure description. This compound presents layers of ET molecules parallel to the ac plane alternating with layers of the tcnoetOH ${ }^{-}$anions (Figure 3). The ET molecules are packed in parallel chains although the molecules of one chain are twisted with respect to those of adjacent chains forming the so-called $\alpha$ and $\theta$ packings [56]. Note that although compound $\mathbf{3}$ could be considered as an $\alpha$ phase (since there is only one different cationic layer), following Mori's suggestion to unify both notations [56], we should call compound $\mathbf{3}$ as a $\theta_{80+80}$ multiple $\theta$ phase, since there are two different chains in the layers and each chain contains a repeating unit formed by eight eclipsed molecules with no dislocation (see Figure 3).

Table 6. Crystal data for compounds $\theta-\mathrm{ET}_{2}(\mathrm{tcnoetOH})(3)$ and $\beta "-\mathrm{ET}_{2}(\mathrm{tcnoetOH})(4)$.

\begin{tabular}{crr}
\hline Compounds & \multicolumn{1}{c}{$\mathbf{3}$} & \multicolumn{1}{c}{$\mathbf{4}$} \\
\hline Formula & $\mathrm{C}_{116} \mathrm{H}_{84} \mathrm{~N}_{16} \mathrm{O}_{8} \mathrm{~S}_{64}$ & $\mathrm{C}_{29} \mathrm{H}_{21} \mathrm{~N}_{4} \mathrm{O}_{2} \mathrm{~S}_{16}$ \\
$M$ & 3881.83 & 970.46 \\
Cryst. Syst. & Triclinic & Triclinic \\
Space group & $\mathrm{P}-1$ & $\mathrm{P}-1$ \\
$a(\AA)$ & $17.3403(13)$ & $10.2496(7)$ \\
$b(\AA)$ & $20.1481(15)$ & $11.2314(10)$ \\
$c(\AA)$ & $23.9412(18)$ & $18.0649(11)$ \\
$\alpha\left(^{\circ}\right)$ & $84.225(6)$ & $96.525(6)$ \\
$\beta\left(^{\circ}\right)$ & $69.596(7)$ & $90.593(5)$ \\
$\gamma\left({ }^{\circ}\right)$ & $76.254(6)$ & $115.397(7)$ \\
$V\left(\AA^{3}\right)$ & $7613.6(10)$ & $1,862.4(2)$ \\
$Z$ & 2 & 2 \\
$T\left(\mathrm{~K}^{3}\right)$ & $293(2)$ & $170(2)$ \\
$\rho_{\text {calc }}\left(\mathrm{g} \cdot \mathrm{cm}^{-3}\right)$ & 1.693 & 1.731 \\
\hline
\end{tabular}


Table 6. Cont.

\begin{tabular}{|c|c|c|}
\hline$\mu\left(\mathrm{cm}^{-1}\right)$ & 9.46 & 9.67 \\
\hline$F(000)$ & 3960 & 990 \\
\hline Refl. Collec. & 66,331 & 19,184 \\
\hline Refl. Uniq. & 42,071 & 11,234 \\
\hline$R_{\text {int }}$ & 0.1655 & 0.0361 \\
\hline Refl. Obs $I>2 \sigma(I)$ & 4381 & 6269 \\
\hline$N_{\mathrm{v}}$ & 1257 & 461 \\
\hline${ }^{\mathrm{a}} R 1$ & 0.1015 & 0.0487 \\
\hline${ }^{\mathrm{b}} w R 2$ & 0.1793 & 0.1171 \\
\hline${ }^{\mathrm{c}}$ GooF & 0.758 & 0.888 \\
\hline$\Delta \rho_{\max }\left(\mathrm{e}^{-3}\right)$ & +0.673 & +1.107 \\
\hline$\Delta \rho_{\min }\left(\mathrm{e}^{-3}\right)$ & -0.503 & -0.677 \\
\hline
\end{tabular}

Figure 3. (a) View of the alternating cationic and anionic layers in compound $\mathbf{3}$ along the $b$ axis; (b) View of the ET layer. Dotted lines indicate the $\mathrm{S} \cdots \mathrm{S}$ contacts shorter than the sum of the van der Waals radii; (c) Side view of the ET chains; (d) View of the overlap between neighboring ET molecules in the chain.

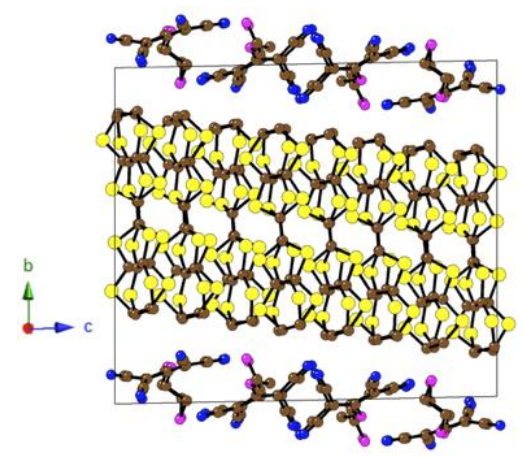

(a)

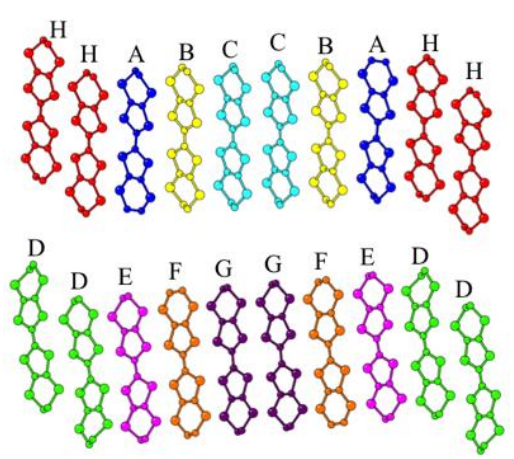

(c)

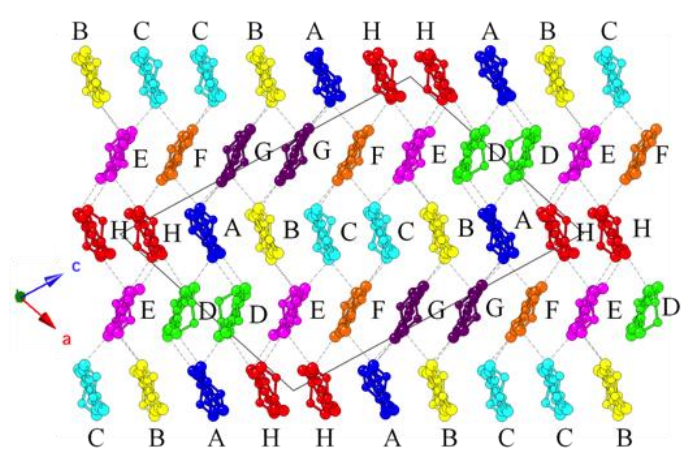

(b)
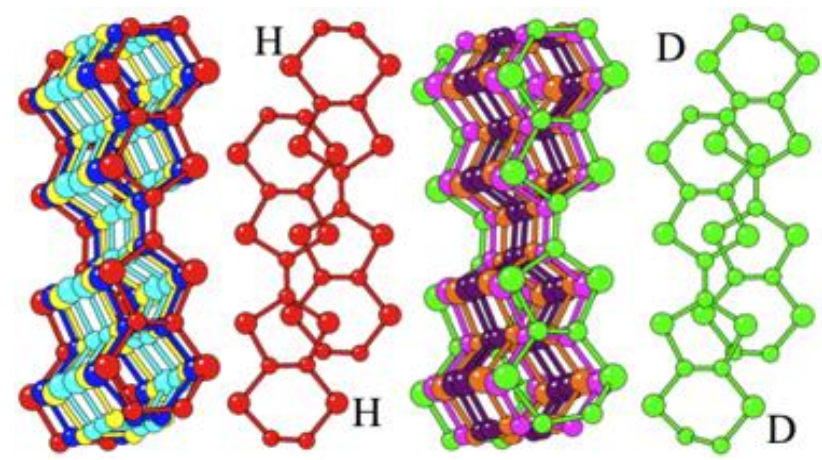

(d)

There are eight independent ET molecules (noted as $\mathrm{A}-\mathrm{H}$ ). Molecules $\mathrm{A}, \mathrm{B}, \mathrm{C}$ and $\mathrm{H}$ form one of the chains following the sequence ...CBAHHABC...and the remaining ET molecules (D, E, F and G) form the other chain with the sequence ...GFEDDEFG... (Figure 3). All the ethylene groups of the 
ET molecules have half chair conformations and are eclipsed except for A and F molecules where they are staggered.

As it is usual in other $\theta$ phases, there are many inter-chains $S \cdots S$ contacts shorter than the sum of the van der Waals radii (3.60 ̊) (Table 7). Furthermore, there are also three short cation-anion $S \cdots \mathrm{N}$ contacts shorter than the sum of the van der Walls radii (3.35 A) implying ET molecules of B, C and E-type (Table 7). The analysis of the charge of each ET molecule shows an inhomogeneous charge distribution with approximate charges of $0.9,0.3,0.7,0.4,0.3,0.4,0.6$ and 0.2 for molecules A-H, respectively, giving a total charge of $c a .+4$ for the eight ET molecules, in agreement with the stoichiometry of compound $\mathbf{3}$ and with the presence of four tcnoetOH ${ }^{-}$anions in the anionic layer per eight ET molecules [54].

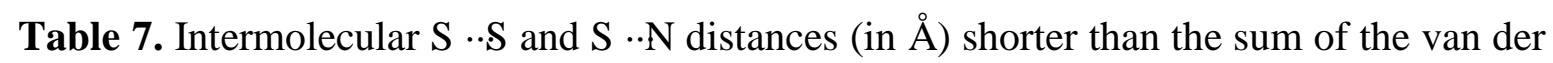
Waals radii (3.60 and $3.35 \AA$, respectively) in compound 3 .

\begin{tabular}{cccccc}
\hline Atoms & Distance & Atoms & Distance & Atoms & Distance \\
\hline S3A-S8G & $3.490(6)$ & S3B-S5G & $3.552(6)$ & S3C-S5F & $3.559(6)$ \\
S5A-S6G & $3.582(6)$ & S5B-S2G & $3.575(6)$ & S6C-S5E & $3.548(6)$ \\
S5A-S2F & $3.553(7)$ & S7B-S5G & $3.526(6)$ & S7C-S5F & $3.442(6)$ \\
S6A-S5D & $3.547(8)$ & S8B-S3E & $3.531(7)$ & S8C-S7F & $3.592(8)$ \\
S7A-S8G & $3.551(6)$ & S8B-S7E & $3.462(8)$ & S2E-S5H & $3.596(6)$ \\
S8A-S6D & $3.525(6)$ & S4D-S6H & $3.527(7)$ & S7B-N32 & $3.30(1)$ \\
S8A-S7D & $3.484(8)$ & S8F-S3H & $3.494(6)$ & S7C-N34 & $3.17(1)$ \\
S8E-S6H & $3.536(6)$ & S6E-S8H & $3.520(6)$ & S8E-N14 & $3.28(1)$ \\
\hline
\end{tabular}

Compound 4 also presents a layered structure (Figure 4) with anionic and cationic layers alternating along the $c$ axis. The cationic layer is formed by two independent ET molecules (A and B) packed in parallel chains with all the molecules parallel and tilted with respect to the chain direction, giving rise to the so-called $\beta "$ phase (Figure 4) [57]. The chains present a repeating unit formed by four ET molecules following the sequence ...AABB... and present three dislocations along this repeating unit, giving rise to a $\beta^{\prime \prime} 43$ phase according to Mori's notation [57].

Figure 4. (a) View of the alternating cationic and anionic layers in compound 4 along the $c$ axis; (b) View of the ET layer. Dotted lines indicate the S...S contacts shorter than the sum of the van der Waals radii; (c) Side view of the ET chains; (d) View of the overlap between neighboring ET molecules in the chain.

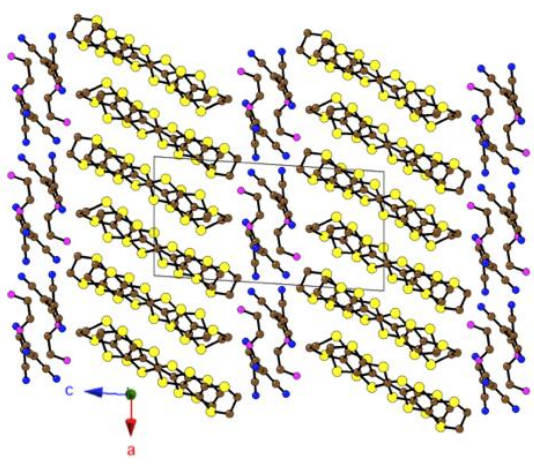

(a)

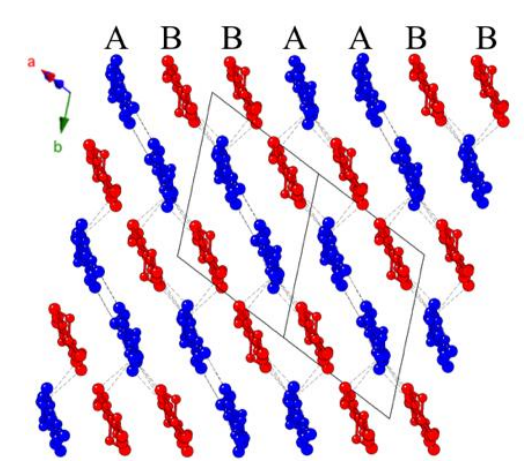

(b) 
Figure 4. Cont.

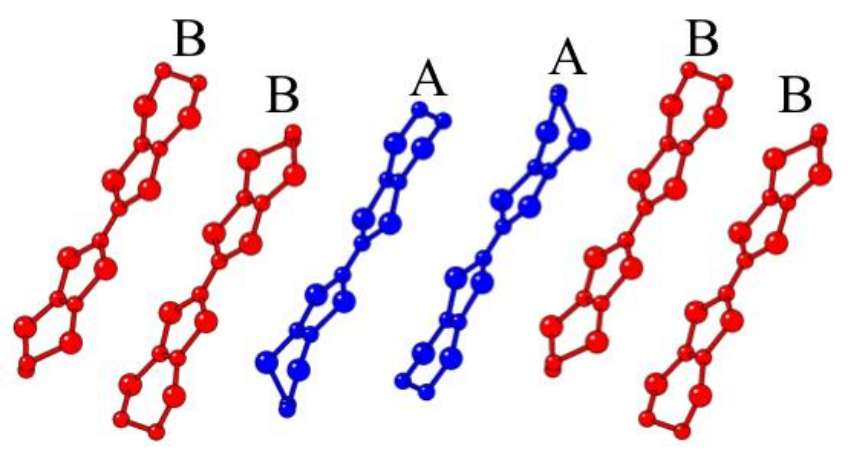

(c)
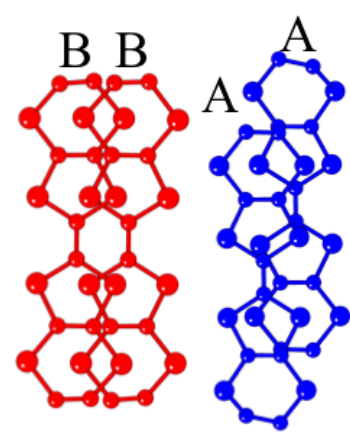

(d)

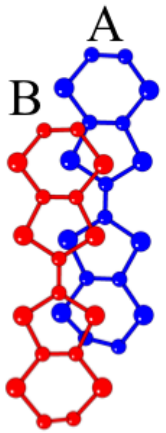

The ethylene groups of the A-type ET molecules present a half-chair and a boat conformation whereas the B-type molecules present a staggered half chair conformation. As in other $\beta^{\prime \prime}$ phases, there are many inter-chain $\mathrm{S} \cdots \mathrm{S}$ contacts shorter than the sum of the van der Waals radii (Table 8).

Table 8. Intermolecular S $\cdots \mathrm{S}$ distances (in $\AA$ ) shorter than the sum of the van der Waals radii $(3.6 \AA)$ in compound 4 .

\begin{tabular}{cccc}
\hline atoms & distance & atoms & distance \\
\hline S1A-S7B & $3.502(1)$ & S7A-S1B & $3.506(2)$ \\
S4A-S6A & $3.494(1)$ & S7A-S4B & $3.501(1)$ \\
S5A-S7B & $3.529(1)$ & S7A-S5B & $3.354(2)$ \\
S6A-S8A & $3.357(1)$ & S7A-S8B & $3.573(1)$ \\
\hline
\end{tabular}

An estimation of the charge of the two ET molecules show a checkerboard-type charge distribution (Figure 4b) since the A-type ET molecule presents an approximate charge of $+1 / 4$ whereas the B-type molecule bears a charge of $c a .+3 / 4$, giving an overall charge of +1 per two ET molecules, in agreement with the single negative charge of the tcnoet $\mathrm{OH}^{-}$anion and the stoichiometry of the salt [54].

\subsubsection{Structure of $\beta "-(\mathrm{ET})_{2}(\mathrm{tcnoprOH}) \cdot\left(\mathrm{CHCl}_{2} \mathrm{CH}_{2} \mathrm{Cl}\right)_{0.5}(\mathbf{5})$}

Compound 5 crystallizes in the triclinic space group P-1. Crystal and refinement data are shown in Table 9.

Table 9. Crystal data for compound $\beta$ "- $\mathrm{ET}_{2}(\mathrm{tcnoprOH})\left(\mathrm{CHCl}_{2} \mathrm{CH}_{2} \mathrm{Cl}\right)_{0.5}(\mathbf{5})$.

\begin{tabular}{lr}
\hline Compound & \multicolumn{1}{c}{$\mathbf{5}$} \\
\hline Formula & $\mathrm{C}_{31} \mathrm{H}_{24.5} \mathrm{Cl}_{1.5} \mathrm{~N}_{4} \mathrm{O}_{2} \mathrm{~S}_{16}$ \\
$M$ & 1051.18 \\
Cryst Syst & Triclinic \\
Space group & $\mathrm{P}-1$ \\
$a(\AA)$ & $7.6688(3)$ \\
$b(\AA)$ & $12.6432(4)$ \\
$c(\AA)$ & $22.6204(5)$ \\
$\alpha\left(^{\circ}\right)$ & $98.430(2)$ \\
\hline
\end{tabular}


Table 9. Cont.

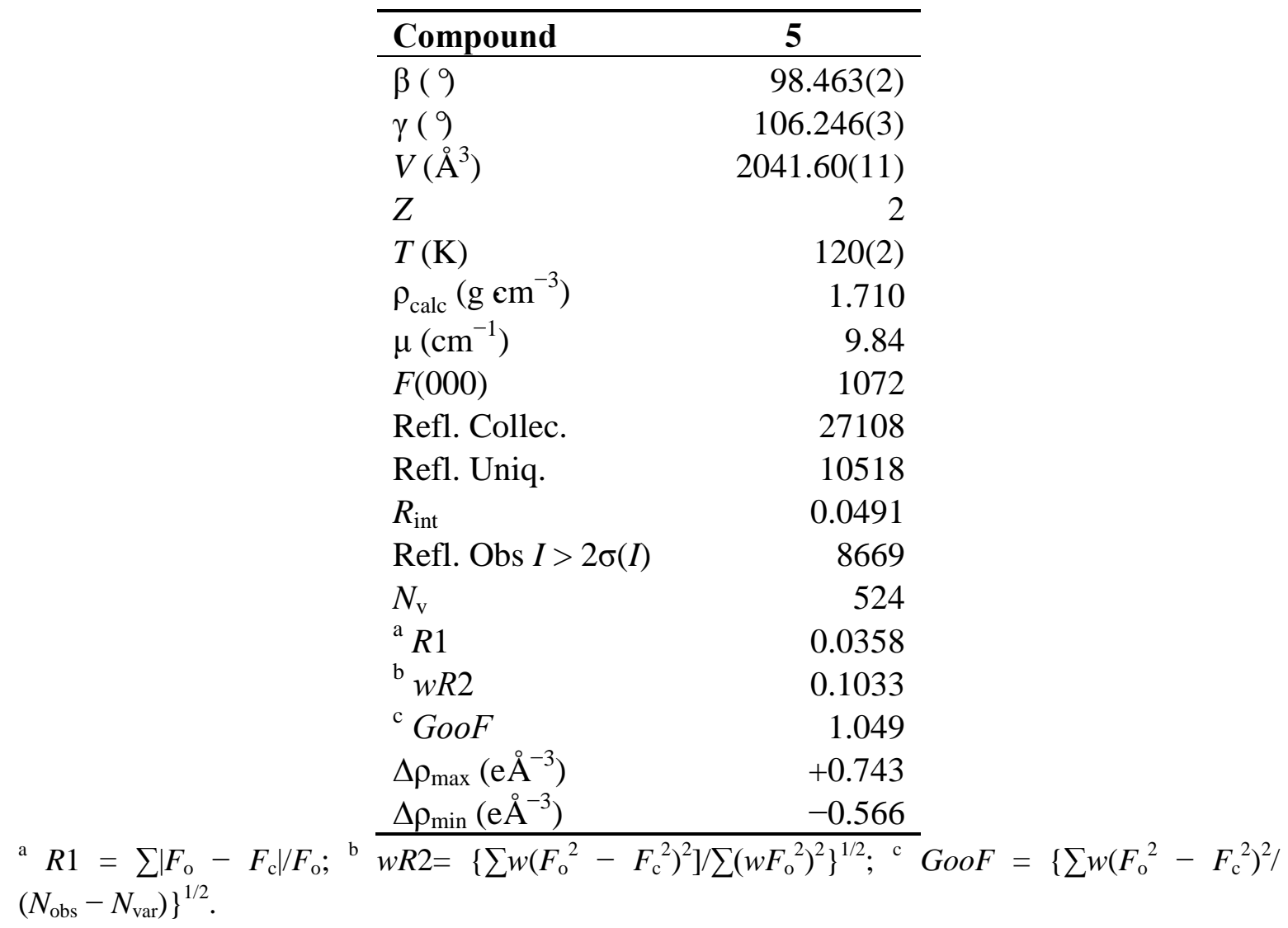

Compound 5 presents an alternating layered structure with the ET molecules forming a $\beta$ " packing (see above) (Figure 5). As observed in compound 4, the chains are formed by two independent ET molecules (A and $\mathrm{B}$ ) and present a repeating unit formed by four ET molecules following the sequence ...AABB... although now there are no dislocations along this repeating unit, giving rise to a $\beta^{\prime \prime} 40$ phase according to Mori's notation (Figure 5) [57].

Figure 5. (a) View of the alternating cationic and anionic layers in compound $\mathbf{5}$ along the $c$ axis; (b) View of the ET layer. Dotted lines indicate the $S$...S contacts shorter than the sum of the van der Waals radii; (c) Side view of the ET chains; (d) View of the overlap between neighboring ET molecules in the chain. The disorder on the ET molecule, the tcnoprOH ${ }^{-}$ anion and the solvent has been removed for clarity.

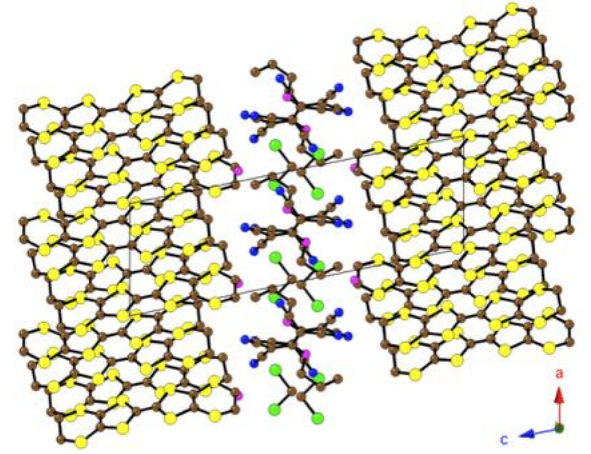

(a)

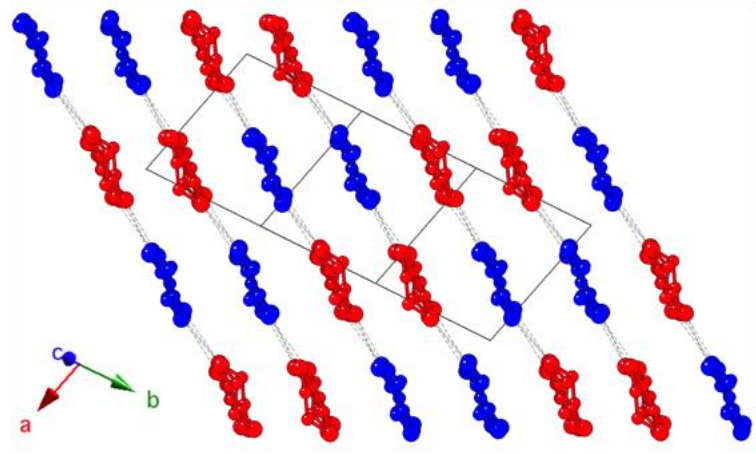

(b) 
Figure 5. Cont.

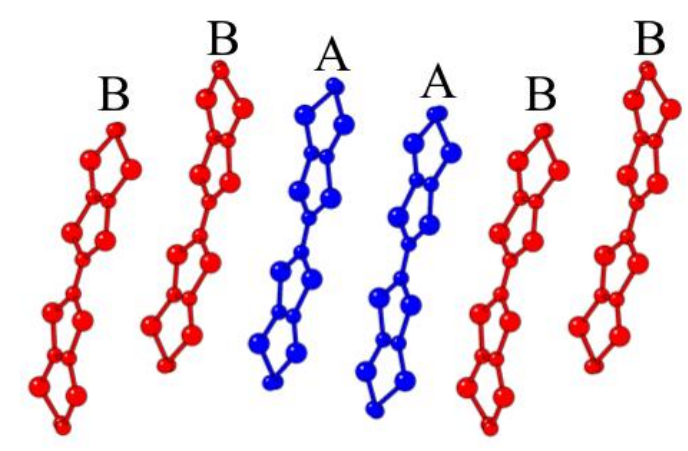

(c)

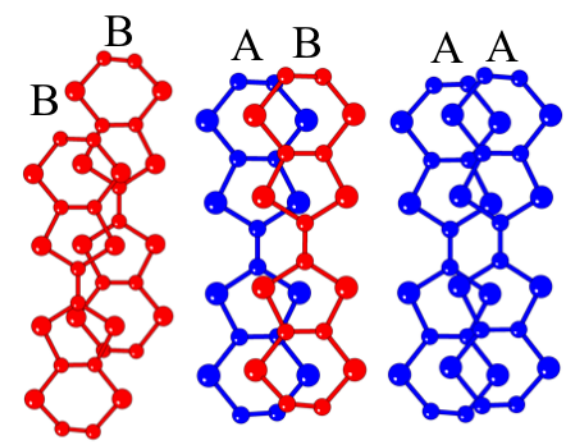

(d)

The ethylene groups of the ET molecules present an eclipsed half-chair conformation although we have observed a partial disorder in the ethylene group C9-C10 of one ET molecule corresponding to two positions with occupancies factors of 0.28 and 0.72 , labelled as C9A/C9B and C10A/C10B, respectively. An additional small disorder has also been detected on the $-\mathrm{CH}_{2} \mathrm{CH}_{2} \mathrm{OH}$ group of the tcnoprOH ${ }^{-}$anion leading to two statistical positions for carbon $\mathrm{C} 29$ and $\mathrm{C} 30$, labelled as $\mathrm{C} 29 \mathrm{~A} / \mathrm{C} 29 \mathrm{~B}$ and $\mathrm{C} 30 \mathrm{~A} / \mathrm{C} 30 \mathrm{~B}$ with occupancies factors of 0.89 and 0.11 for $\mathrm{A}$ and $\mathrm{B}$ positions, respectively. As is common in the $\beta^{\prime \prime}$ phases, compound 5 presents several $S \cdots S$ contacts shorter than the sum of the van der Waals radii (Table 10).

Table 10. Intermolecular S $\cdots S$ distances (in $\AA$ ) shorter than the sum of the van der Waals radii $(3.60 \AA)$ in compound 5 .

\begin{tabular}{cccc}
\hline atoms & distance & atoms & distance \\
\hline S3-S16 & $3.446(1)$ & S6-S9 & $3.441(1)$ \\
S4-S15 & $3.404(1)$ & S6-S13 & $3.424(1)$ \\
S5-S14 & $3.376(1)$ & S7-S16 & $3.429(1)$ \\
S5-S10 & $3.396(1)$ & S8-S15 & $3.370(1)$ \\
\hline
\end{tabular}

The analysis of the bond lengths in compound $\mathbf{5}$ shows an homogeneous charge distribution with both ET molecules (A and B) bearing a charge close to +0.5 , in agreement with the stoichiometry $(2: 1)$ and the anionic charge $(-1)[54]$.

The anionic layers, parallel to the $a c$ plane, contain tcnoprOH ${ }^{-}$anions and half a disordered $\mathrm{CHCl}_{2} \mathrm{CH}_{2} \mathrm{Cl}$ molecule.

\subsection{Electrical Properties}

The dc electrical conductivity of compounds 1-4 shows similar thermal behaviors although with different room temperature conductivities values ranging from $10^{-4} \mathrm{~S} \cdot \mathrm{cm}^{-1}$ in compound 2 to $3.8 \mathrm{~S} \cdot \mathrm{cm}^{-1}$ in compound 4 (Table 11). When the temperature is decreased, the resistivity of compounds 1-4 increases and reaches the limiting resistance of our equipment at temperatures in the range 150-250 K (Figure 6). This thermal behavior suggests that compounds $\mathbf{1 - 4}$ are semiconductors as confirmed by the Arrhenius plots (Figure 7) that show straight lines in all cases with activations energies in the range 110-510 meV (Table 11). 
Table 11. Room temperature electrical conductivity values, activation energies and approximate charge distributions in compounds $\mathbf{1}-\mathbf{5}$.

\begin{tabular}{crrr}
\hline Compound & $\boldsymbol{\sigma}_{\mathbf{3 0 0 K}}\left({\left.\mathbf{S} \cdot \mathbf{c m}^{-\mathbf{1}}\right)}\right.$ & $\boldsymbol{E}_{\mathbf{a}}(\mathbf{m e V})$ & ET Charge \\
\hline $\mathbf{1}$ & 0.18 & 110 & $0.5 / 0.5$ \\
$\mathbf{2}$ & $10^{-4}$ & 175 & $0.5 / 0.5$ \\
$\mathbf{3}$ & & 326 & $0.9 / 0.3 / 0.7 / 0.4$ \\
$\mathbf{4}$ & 0.05 & & $0.3 / 0.4 / 0.6 / 0.2$ \\
$\mathbf{5}$ & 3.8 & 510 & $0.25 / 0.75$ \\
\hline
\end{tabular}

Figure 6. Thermal variation of the dc electrical conductivity of compounds 1-5.

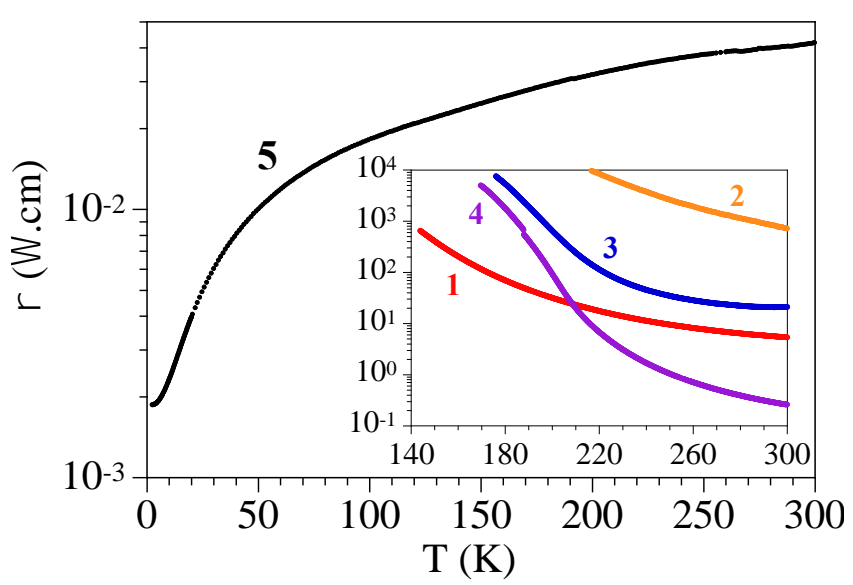

Figure 7. Arrhenius plot of the dc conductivity for compounds 1-4.

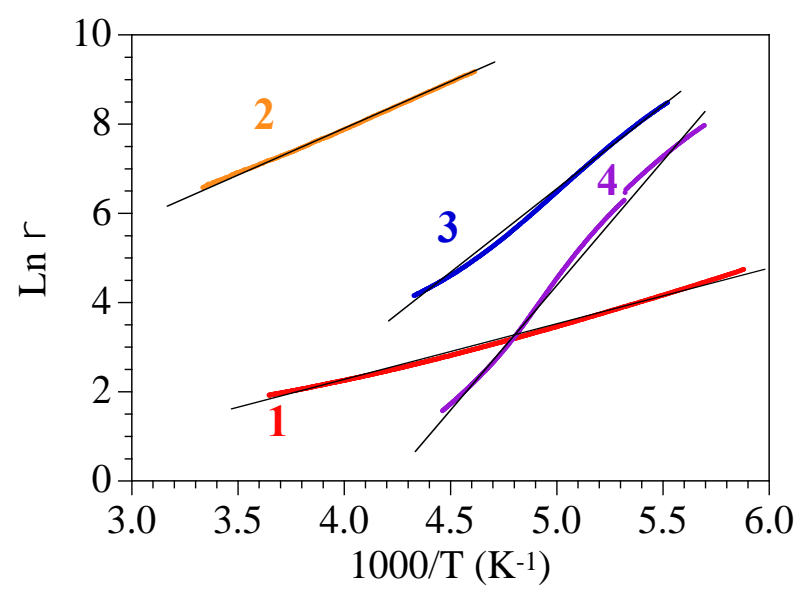

The relatively high conductivities found in compounds $\mathbf{1}$ and 3-5 may be attributed to the presence in all the salts of partial oxidation degrees and of many intermolecular $S \cdots S$ short contacts. The lower conductivity found in compound $\mathbf{2}$ compared with all the others, agrees with the much lower quality of the single crystals, as also observed in the X-ray diffraction study (see below). The activation energies found in compounds 1-4 correlate well with the approximate charge distribution. Thus, compounds $\mathbf{1}$ and $\mathbf{2}$ present homogeneous charge distributions and the lowest activation energies (Table 11) whereas compounds 3 and $\mathbf{4}$ present inhomogeneous charge distributions and the highest activation energies. As expected, the metallic salt 5 presents a homogeneous charge distribution (Table 11). 
Compound 5 shows a higher room temperature conductivity $\left(24 \mathrm{~S} \cdot \mathrm{cm}^{-1}\right)$ and interestingly, its resistivity decreases as the temperature is decreased, in a typical metallic behavior, reaching a conductivity value of $c a .530 \mathrm{~S} \cdot \mathrm{cm}^{-1}$ at the lowest measured temperature $(0.4 \mathrm{~K})$. Note that no superconducting transition is observed in any of the six measured crystals of this compound and, in fact, some of them show a smooth broad minimum in the resistivity plot at very low temperatures, suggesting the presence of a metal-semiconducting transition at low temperatures.

\section{Experimental Section}

\subsection{Synthesis}

The five salts have been prepared by electrochemical oxidation of the donor (ET) in the presence of the corresponding anions (tcpd ${ }^{2-}$ for $\mathbf{1}$ and $\mathbf{2}$, tcnoetOH ${ }^{-}$for $\mathbf{3}$ and $\mathbf{4}$ and tcnoprOH ${ }^{-}$for $\mathbf{5}$ ). The precursor polycyano salts used in compounds $\mathbf{1}-\mathbf{4}$ are the corresponding $\mathrm{K}^{+}$salts: $\mathrm{K}_{2}$ (tcpd) [58] and $\mathrm{K}(\mathrm{tcnoetOH})$ [59]. For the synthesis of compound 5 we have used the $\mathrm{Cu}(\mathrm{tcnoprOH})_{2}$ precursor salt [49], which was prepared by metathesis of the corresponding $\mathrm{K}^{+}$salt with $\mathrm{CuCl}_{2}$ in aqueous medium [50]. The exact synthetic conditions used to obtain compounds $\mathbf{1}-\mathbf{5}$ are indicated in Table 12.

Table 12. Experimental conditions used for the synthesis of compounds 1-5.

\begin{tabular}{|c|c|c|c|c|c|}
\hline Salt & Anode & Cathode & Current $(\boldsymbol{\mu} \mathbf{A})$ & Days & Aspect \\
\hline 1 & $\begin{array}{c}10 \mathrm{mg} \mathrm{ET} \\
10 \mathrm{~mL} \mathrm{CH}_{2} \mathrm{Cl}_{2}\end{array}$ & $\begin{array}{c}28 \mathrm{mg} \mathrm{K} \text { tcpd } \cdot 2 \mathrm{H}_{2} \mathrm{O} \\
10 \mathrm{~mL} \mathrm{THF} \\
\end{array}$ & $0.5 \mu \mathrm{A}$ & 30 & $\begin{array}{c}\text { dark brown } \\
\text { prisms }\end{array}$ \\
\hline 2 & $\begin{array}{c}10 \mathrm{mg} \mathrm{ET} \\
10 \mathrm{~mL} \mathrm{CH}_{2} \mathrm{Cl}_{2} \\
2 \mathrm{mLEtOH} \\
2 \text { drops } \mathrm{H}_{2} \mathrm{O}\end{array}$ & 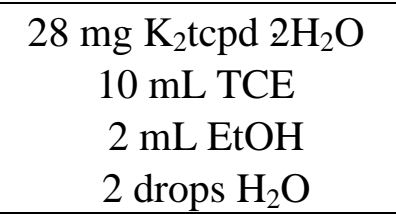 & $0.5 \mu \mathrm{A}$ & 32 & black prisms \\
\hline $3 / 4$ & $\begin{array}{c}10 \mathrm{mg} \mathrm{ET} \\
10 \mathrm{~mL} \mathrm{CH}_{2} \mathrm{Cl}_{2}\end{array}$ & $\begin{array}{c}24 \mathrm{mg} \mathrm{K}(\text { tcnoetOH }) \\
10 \mathrm{~mL} \mathrm{TCE} \\
2 \mathrm{~mL} \mathrm{EtOH} \\
\end{array}$ & $0.5 \mu \mathrm{A}$ & 20 & $\begin{array}{l}\text { black plates }(\mathbf{3}) \\
\text { black needles }(\mathbf{4})\end{array}$ \\
\hline 5 & $\begin{array}{c}10 \mathrm{mg} \mathrm{ET} \\
10 \mathrm{~mL} \mathrm{TCE} \\
1 \mathrm{~mL} \mathrm{EtOH}\end{array}$ & $\begin{array}{c}40 \mathrm{mg} \mathrm{Cu}(\text { tcnoprOH })_{2} \\
10 \mathrm{~mL} \mathrm{TCE} \\
1 \mathrm{~mL} \mathrm{EtOH}\end{array}$ & $0.5 \mu \mathrm{A}$ & 30 & $\begin{array}{l}\text { brown shiny } \\
\text { prisms }\end{array}$ \\
\hline
\end{tabular}

\subsection{X-ray Crystallography}

Crystallographic data of compound 1 were collected at $293 \mathrm{~K}$ with a R-Axis Rapid Rigaku MSC diffractometer with monochromatic $\mathrm{Cu}-\mathrm{K} \alpha$ radiation $(\lambda=1.54178 \AA)$ and a curved image plate detector. A small crystal was used to collect the data. At $293 \mathrm{~K}$, the full sphere data collection was performed using $\varphi$ scans and $\omega$ scans with an exposure time of $36 \mathrm{~s}$ per degree. The unit cell determination and data reduction were performed using the crystal clear program suite [60] on the full set of data. Crystallographic data were collected using an Oxford Diffraction Xcalibur $\kappa$-CCD diffractometer (for compounds 2-4) and an Oxford Diffraction Supernova diffractometer (for compound 5) with Mo-K $\alpha$ radiation $(\lambda=0.71073 \AA)$. The full sphere data collection was performed using $\varphi$ scans and $\omega$ scans. The unit cell determination and data reduction were performed using the 
CrysAlis program suite [61] on the full set of data. For the five compounds, the crystal structures were solved by direct methods and successive Fourier difference syntheses with the SIR97 program [62] for compounds 2-4 and SHELXS-97 program [63] for compounds 1 and 5. The refinements of the crystal structure were performed on $F^{2}$ by weighted anisotropic or mixed isotropic/anisotropic full-matrix least squares methods using the SHELXL97 program [63] for all compounds. Both pieces of software were used within the WINGX or the OLEX2 package $[64,65]$. No absorption correction was needed owing to the low absorption coefficient of these complexes. Due to the low quality and the small size of the crystals, anisotropic/isotropic mixed model were used for compounds $\mathbf{2}$ and $\mathbf{3}$. Thus, an anisotropic refinement has been performed for the $\mathrm{S}, \mathrm{O}$ and $\mathrm{N}$ atoms for compound $\mathbf{3}$ whereas only the $\mathrm{S}$ atoms have been anisotropically refined for compound 2. For compound 1, 4 and 5, all non-H atoms were refined anisotropically. For all compounds, $\mathrm{H}$ atoms were treated according to the riding model during refinement with isotropic displacement parameters, corresponding to the $\mathrm{C}$ atom they are linked to.

Additionally, the crystal of $\mathbf{1}$ presents a small fraction of twinned part that may be due to a rotation of $\pi$ radians around the $a$ and the $c$ crystallographic axes. This twin generates a small disorder of the whole crystal structure. According to the low fraction of the twinned part that can be estimated to $8 \%$, such a disorder could be solved only for the sulfur atoms of the ET molecules and refined isotropically. The disordered ET molecules appear to be twisted of about $30^{\circ}$ and in the same plane that the ET molecules from the main crystal part.

Crystallographic data have been deposited in the Cambridge Crystallographic Data Centre (CCDC numbers $855227,871616,871618,871619$ and 871625 for $\mathbf{1}-\mathbf{5}$ respectively). Copies of this data can be obtained free of charge from the Director, CCDC, 12 Union Road, Cambridge, CB2 1EZ, UK or via the web application [66].

\subsection{Electrical Conductivity Measurements}

DC electrical conductivity measurements were carried out with the four contacts method on several single crystals of samples $\mathbf{1}-\mathbf{4}$ in the temperature range 300-2 K (300-0.4 K for 5), although, given the dimensions of the crystals and their high resistivity, in most cases the detection limit of our equipment $\left(5 \times 10^{9} \Omega\right)$ was attained between 100 and $200 \mathrm{~K}$. The contacts were made with Pt wires $(25 \mu \mathrm{m}$ diameter) using graphite paste. The samples were measured in Quantum Design PPMS-9 equipment. All the conductivity quoted values have been measured in the voltage range where the crystals are Ohmic conductors. For each compound all the measured crystals showed similar conductivity values and thermal behaviors. The cooling and warming rates were 0.5 and $1 \mathrm{~K} / \mathrm{min}$ and the results were, within experimental error, identical in the cooling and warming scans.

\section{Conclusions}

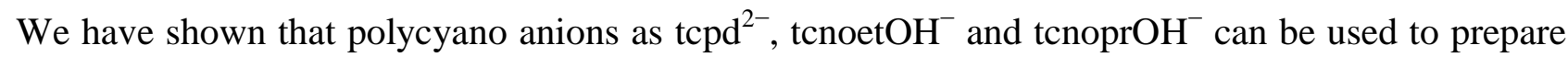
up to five novel conducting radical salts with the organic donor ET. All the structures show the typical alternating cationic (ET) and anionic (polycyano plus solvent) layers. Interestingly, in the case of the anion tcnoetOH ${ }^{-}$we have been able to prepare two different polymorphs: $\theta-\mathrm{ET}_{2}(\mathrm{tcnoetOH})(3)$ and $\beta "-\mathrm{ET}_{2}(\mathrm{tcnoetOH})(\mathbf{4})$ with the same stoichiometry and under the same synthetic conditions. The anion $\mathrm{tcpd}^{2-}$ has yielded two different salts with slightly different synthetic conditions: $\alpha^{\prime}-(\mathrm{ET})_{4}(\mathrm{tcpd}) \cdot \mathrm{THF}(\mathbf{1})$ 
and $\alpha^{\prime}-(\mathrm{ET})_{4}(\mathrm{tcpd}) \cdot 2 \mathrm{H}_{2} \mathrm{O}(2)$ showing the same phase and composition but different solvent molecules in the anionic layers. Finally, the anion tcnoprOH ${ }^{-}$has given rise to a $\beta "$ phase: $\beta^{\prime \prime}$-(ET) $)_{2}$ (tcnoprOH) $\left(\mathrm{CHCl}_{2} \mathrm{CH}_{2} \mathrm{Cl}\right)_{0.5}(5)$ containing half a $\mathrm{CHCl}_{2} \mathrm{CH}_{2} \mathrm{Cl}$ molecule in the anionic layer. The homogeneous charge distribution and the presence of many short intermolecular $\mathrm{S} \cdots \mathrm{S}$ contacts give rise to high conductivity values in all cases except in compound $\mathbf{2}$, probably due to the low quality of the single crystals. Compound $\mathbf{5}$, shows a metallic behavior although no superconducting transition above $0.4 \mathrm{~K}$.

\section{Acknowledgments}

We thank the Spanish Ministerio de Economía y Competitividad (Projects Consolider-Ingenio in Molecular Nanoscience CSD2007-00010 and CTQ-2011-26507), the Generalitat Valenciana (Project Prometeo 2009/95) and Centre National de la Recherche Scientifique, CNRS (PICS project number 5137) for financial support.

\section{Conflict of Interest}

The authors declare no conflict of interest.

\section{References}

1. Ferraris, J.; Cowan, D.O.; Walatka, V.; Perlstein, J.H. Electron transfer in a new highly conducting donor-acceptor complex. J. Am. Chem. Soc. 1973, 95, 948-949.

2. Jerome, D.; Mazaud, A.; Ribault, M.; Bechgaard, K. Superconductivity in a synthetic organic conductor (TMTSF) ${ }_{2} \mathrm{PF}_{6}$. J. Phys. Lett. 1980, 41, 95-98.

3. Enoki, T.; Miyazaki, A. Magnetic TTF-based charge-transfer complexes. Chem. Rev. 2004, 104, 5449-5478.

4. Kobayashi, H.; Kobayashi, A.; Cassoux, P. BETS as a source of molecular magnetic superconductors (BETS $=$ bis(ethylenedithio)tetraselenafulvalene). Chem. Soc. Rev. 2000, 29, $325-333$.

5. Kobayashi, H.; Tomita, H.; Naito, T.; Kobayashi, A.; Sakai, F.; Watanabe, T.; Cassoux, P. New BETS conductors with magnetic anions (BETS = bis(ethylenedithio)tetraselenafulvalene). J. Am. Chem. Soc. 1996, 118, 368-377.

6. Graham, A.W.; Kurmoo, M.; Day, P. $\beta "(\mathrm{BEDT}-\mathrm{TTF})_{4}\left[\left(\mathrm{H}_{2} \mathrm{O}\right) \mathrm{Fe}\left(\mathrm{C}_{2} \mathrm{O}_{4}\right)_{3}\right] . \mathrm{PhCN}$ : The first molecular superconductor containing paramagnetic metal Ions. J. Chem. Soc. Chem. Commun. 1995, doi:10.1039/C39950002061.

7. Coronado, E.; Curreli, S.; Gimenez-Saiz, C.; Gómez-García, C.J. The series of molecular conductors and superconductors $\mathrm{ET}_{4}\left[\mathrm{AFe}\left(\mathrm{C}_{2} \mathrm{O}_{4}\right)_{3}\right] \cdot \mathrm{PhX}(\mathrm{ET}=$ bis(ethylenedithio)tetrathia-fulvalene; $\left(\mathrm{C}_{2} \mathrm{O}_{4}\right)^{2-}=$ Oxalate; $\mathrm{A}^{+}=\mathrm{H}_{3} \mathrm{O}^{+}, \mathrm{K}^{+} ; \mathrm{X}=\mathrm{F}, \mathrm{Cl}, \mathrm{Br}$, and I): Influence of the halobenzene guest molecules on the crystal structure and superconducting properties. Inorg. Chem. 2012, 51, 1111-1126. 
8. Kurmoo, M.; Graham, A.W.; Day, P.; Coles, S.J.; Hursthouse, M.B.; Caulfield, J.L.; Singleton, J.; Pratt, F.L.; Hayes, W. Superconducting and semiconducting magnetic charge transfer salts: (BEDT-TTF $)_{4} \mathrm{AFe}\left(\mathrm{C}_{2} \mathrm{O}_{4}\right)_{3} \cdot \mathrm{C}_{6} \mathrm{H}_{5} \mathrm{CN}\left(\mathrm{A}=\mathrm{H}_{2} \mathrm{O}, \mathrm{K}, \mathrm{NH}_{4}\right)$. J. Am. Chem. Soc. 1995, 117, 12209-12217.

9. Martin, L.; Turner, S.S.; Day, P.; Guionneau, P.; Howard, J.A.K.; Hibbs, D.E.; Light, M.E.; Hursthouse, M.B.; Uruichi, M.; Yakushi, K. Crystal chemistry and physical properties of superconducting and semiconducting charge transfer salts of the type (BEDT-TTF) 4 $\left[\mathrm{A}^{\mathrm{I}} \mathrm{M}^{\mathrm{III}}\left(\mathrm{C}_{2} \mathrm{O}_{4}\right)_{3}\right] . \mathrm{PhCN} \quad\left(\mathrm{A}^{\mathrm{I}}=\mathrm{H}_{3} \mathrm{O}, \mathrm{NH}_{4}, \mathrm{~K} ; \mathrm{M}^{\mathrm{III}}=\mathrm{Cr}, \mathrm{Fe}, \mathrm{Co}, \mathrm{Al} ; \mathrm{BEDT}-\mathrm{TTF}=\right.$ bis(ethylenedithio)tetrathiafulvalene). Inorg. Chem. 2001, 40, 1363-1371.

10. Coronado, E.; Day, P. Magnetic molecular conductors. Chem. Rev. 2004, 104, 5419-5448.

11. Prokhorova, T.G.; Buravov, L.I.; Yagubskii, E.B.; Zorina, L.V.; Khasanov, S.S.; Simonov, S.V.; Shibaeva, R.P.; Korobenko, A.V.; Zverev, V.N. Effect of electrocrystallization medium on quality, structural features, and conducting properties of single crystals of the (BEDT-TTF) 4 $\mathrm{A}^{\mathrm{I}}\left[\mathrm{Fe}^{\mathrm{III}}\left(\mathrm{C}_{2} \mathrm{O}_{4}\right)_{3}\right] . \mathrm{G}$ family. CrystEngComm 2011, 13, 537-545.

12. Coronado, E.; Gómez-García, C.J. Polyoxometalates-from magnetic clusters to molecular materials. Comments Inorg. Chem. 1995, 17, 255-281.

13. Gómez-García, C.J.; Gimenezsaiz, C.; Triki, S.; Coronado, E.; Lemagueres, P.; Ouahab, L.; Ducasse, L.; Sourisseau, C.; Delhaes, P. Coexistence of magnetic and delocalized electrons in hybrid molecular materials - The series of organic-inorganic radical salts (BEDT-TTF) $)_{8}\left[\mathrm{XW}_{12} \mathrm{O}_{40}\right]$ $(\text { Solv })_{n}\left(\mathrm{X}=2\left(\mathrm{H}^{+}\right), \mathrm{B}^{\mathrm{III}}, \mathrm{Si}^{\mathrm{IV}}, \mathrm{Cu}^{\mathrm{II}}, \mathrm{Co}^{\mathrm{II}}, \mathrm{Fe}^{\mathrm{III}} \mathrm{Solv}=\mathrm{H}_{2} \mathrm{O}, \mathrm{CH}_{3} \mathrm{CN}\right)$. Inorg. Chem. 1995, 34, 4139-4151.

14. Gómez-García, C.J.; Ouahab, L.; Gimenez-Saiz, C.; Triki, S.; Coronado, E.; Delhaes, P. Coexistence of mobile and localized-electrons in bis(ethylene)dithiotetrathiafulvalene (BEDT-TTF) radical salts with paramagnetic polyoxometalates-Synthesis and physical-properties of (BEDT-TTF $)_{8}\left[\mathrm{CoW}_{12} \mathrm{O}_{40}\right]$ 5.5 $\mathrm{H}_{2} \mathrm{O}$. Angew. Chem. Int. Ed. Engl.1994, 33, 223-226.

15. Coronado, E.; Galan-Mascaros, J.R.; Gimenez-Saiz, C.; Gómez-García, C.J.; Triki, S. Hybrid molecular materials based upon magnetic polyoxometalates and organic pi-electron donors: Syntheses, structures, and properties of bis(ethylenedithio)tetrathiafulvalene radical salts with monosubstituted keggin polyoxoanions. J. Am. Chem. Soc. 1998, 120, 4671-4681.

16. Coronado, E.; GalanMascaros, J.R.; GimenezSaiz, C.; Gómez-García, C.J.; Laukhin, V.N. The first radical salt of the polyoxometalate cluster $\left[\mathrm{P}_{2} \mathrm{~W}_{18} \mathrm{O}_{62}\right]^{6-}$ with bis(ethylenedithio)-tetrathiafulvalene (ET): $\mathrm{ET}_{11}\left[\mathrm{P}_{2} \mathrm{~W}_{18} \mathrm{O}_{62}\right] 3 \mathrm{H}_{2} \mathrm{O}$. Adv Mater 1996, 8, 801-803.

17. Coronado, E.; Galan-Mascaros, J.R.; Gómez-García, C.J.; Laukhin, V. Coexistence of ferromagnetism and metallic conductivity in a molecule-based layered compound. Nature $\mathbf{2 0 0 0}$, 408, 447-449.

18. Alberola, A.; Coronado, E.; Galan-Mascaros, J.R.; Gimenez-Saiz, C.; Gómez-García, C.J. A molecular metal ferromagnet from the organic donor bis(ethylenedithio)tetraselenafulvalene and bimetallic oxalate complexes. J. Am. Chem. Soc. 2003, 125, 10774-10775.

19. Coronado, E.; Galan-Mascaros, J.R.; Gómez-García, C.J.; Martinez-Ferrero, E.; van Smaalen, S. Incommensurate nature of the multilayered molecular ferromagnetic metals based on bis(ethylenedithio)tetrathiafulvalene and bimetallic oxalate complexes. Inorg. Chem. 2004, 43, 4808-4810. 
20. Alberola, A.; Coronado, E.; Galan-Mascaros, J.R.; Gimenez-Saiz, C.; Gómez-García, C.J.; Martinez-Ferrero, E.; Murcia-Martinez, A. Multifunctionality in hybrid molecular materials: Design of ferromagnetic molecular metals. Synth. Met. 2003, 135, 687-689.

21. Kini, A.M.; Geiser, U.; Wang, H.H.; Carlson, K.D.; Williams, J.M.; Kwok, W.K.; Vandervoort, K.G.; Thompson, J.E.; Stupka, D.L. A new ambient-pressure organic superconductor, $\kappa-(\mathrm{ET})_{2} \mathrm{Cu}\left[\mathrm{N}(\mathrm{CN})_{2}\right] \mathrm{Br}$, with the highest transition temperature yet observed (Inductive Onset $T_{\mathrm{c}}=11.6 \mathrm{~K}$, Resistive Onset = 12.5 K). Inorg. Chem. 1990, 29, 2555-2557.

22. Komatsu, T.; Nakamura, T.; Matsukawa, N.; Yamochi, H.; Saito, G.; Ito, H.; Ishiguro, T.; Kusunoki, M.; Sakaguchi, K. New ambient-pressure organic superconductors based on BEDT-TTF, $\mathrm{Cu}, \mathrm{N}(\mathrm{CN})_{2}$ and $\mathrm{CN}$ with $T_{\mathrm{c}}=10.7 \mathrm{~K}$ and $3.8 \mathrm{~K}$. Solid State Commun. 1991, 80, 843-847.

23. Kushch, N.D.; Kazakova, A.V.; Buravov, L.I.; Chekhlov, A.N.; Dubrovskii, A.D.; Yagubskii, E.B.; Canadell, E. The First Polymorph, $\kappa^{\prime \prime}-(\mathrm{ET})_{2} \mathrm{Cu}\left[\mathrm{N}(\mathrm{CN})_{2}\right] \mathrm{Cl}$, in the Family of $\kappa-(\mathrm{ET})_{2} \mathrm{Cu}\left[\mathrm{N}(\mathrm{CN})_{2}\right]$ $\mathrm{X}(\mathrm{X}=\mathrm{Cl}, \mathrm{Br}, \mathrm{I})$ radical cation salts. J. Solid State Chem. 2009, 182, 617-621.

24. Geiser, U.; Schlueter, J.A. Conducting organic radical cation salts with organic and organometallic anions. Chem. Rev. 2004, 104, 5203-5242.

25. Hasegawa, T.; Mochida, T.; Kondo, R.; Kagoshima, S.; Iwasa, Y.; Akutagawa, T.; Nakamura, T.; Saito, G. Mixed-stack organic charge-transfer complexes with intercolumnar networks. Phys. Rev. B 2000, 62, 10059-10066.

26. Hasegawa, T.; Inukai, K.; Kagoshima, S.; Sugawara, T.; Mochida, T.; Sugiura, S.; Iwasa, Y. $(\mathrm{BEDT}-\mathrm{TTF})\left(\mathrm{F}_{1} \mathrm{TCNQ}\right)$ and $(\mathrm{BEDT}-\mathrm{TTF})\left(\mathrm{F}_{2} \mathrm{TCNQ}\right)_{\mathrm{x}}(\mathrm{TCNQ})_{1-x}(x \approx 0.5)$ : All-organic metals down to 2 K. Chem. Commun. 1997, doi:10.1039/A700994A.

27. Mori, T.; Inokuchi, H. Structural and electrical properties of (BEDT-TTF)(TCNQ). Solid State Commun. 1986, 59, 355-359.

28. Beno, M.A.; Wang, H.H.; Soderholm, L.; Carlson, K.D.; Hall, L.N.; Nunez, L.; Rummens, H.; Anderson, B.; Schlueter, J.A.; Williams, J.M.; Whangbo, M.H.; Evain, M. Synthesis of the new organic metal $(\mathrm{ET})_{2} \mathrm{C}(\mathrm{CN})_{3}$ and characterization of its metal-insulator phase-transition at approximately-180-K. Inorg. Chem. 1989, 28, 150-154.

29. Yamochi, H.; Tsuji, T.; Saito, G.; Suzuki, T.; Miyashi, T.; Kabuto, C. BEDT-TTF complexes with percyano substituted organic anions. Synth. Met. 1988, 27, A479-A484.

30. Watson, W.H.; Kini, A.M.; Beno, M.A.; Montgomery, L.K.; Wang, H.H.; Carlson, K.D.; Gates, B.D.; Tytko, S.F.; Derose, J.; Cariss, C.; Rohl, C.A.; Williams, J.M. Crystal structure and electrical properties of (BEDT-TTF $)_{2} \mathrm{Cp}(\mathrm{CN})_{5}(\text { Solvent })_{x}$. Synth. Met. 1989, 33, 1-9.

31. Saito, G.; Sekizaki, S.; Konsha, A.; Yamochi, H.; Matsumoto, K.; Kusunoki, M.; Sakaguchi, K. A stable and flexible dianion: 2-Dicyanomethylene-1,1,3,4,5,5-Hexacyanopentenediide (DHCP), and its complex formation. J. Mater. Chem. 2001, 11, 364-373.

32. Aso, Y.; Yui, K.; Ishida, H.; Otsubo, T.; Ogura, F.; Kawamoto, A.; Tanaka, J. Crystal structure of 2,5-bis(dicyanomethylene)-2,5-dihydrothieno[3,2-b]thiophene and bis(ethylenedithio)tetrathiafulvalene complex. Chem. Lett. 1988, 17, 1069-1072.

33. Yamochi, H.; Tada, C.; Sekizaki, S.; Saito, G.; Kusunoki, M.; Sakaguchi, K. Conductive radical cation salts with organic anions of $\left\{\mathrm{RO}-\mathrm{C}\left[\mathrm{C}(\mathrm{CN})_{2}\right]_{2}\right\}$. Mol. Cryst. Liquid Cryst. 1996, 284, 379-390. 
34. Sekizaki, S.; Matsukawa, N.; Yamochi, H.; Saito, G. Variety of BEDT-TTF salts with organic polycyano anions. Synth. Met. 2003, 133-134, 455-457.

35. Kazakova, A.V.; Kushch, N.D.; Chekhlov, A.N.; Dubrovskii, A.D.; Yagubskii, E.B.; Van, K.V. New multicomponent organic semiconductors based on ET with Polymeric anions: $\alpha^{\prime}-(\mathrm{ET})_{2} \mathrm{~N}(\mathrm{CN})_{2} \cdot 2 \mathrm{H}_{2} \mathrm{O}$ and $\alpha "-(\mathrm{ET})_{6}\left(\mathrm{NO}_{3}\right)_{3} \cdot 2 \mathrm{C}_{2} \mathrm{H}_{5} \mathrm{O}_{2} \mathrm{~N}_{3}$. Russ. J. Gen. Chem. 2008, 78, 6-13.

36. Bu, X.; Coppens, P.; Lederle, B.; Naughton, M.J. Structure of (BEDT-TTF $)_{2} \mathrm{~N}(\mathrm{CN})_{2}$. Acta Cryst. C 1992, 48, 1560-1561.

37. Schlueter, J.; Geiser, U.; Manson, J. Anionic dicyanamide frameworks as possible components of multifunctional materials. J. Phys. IV 2004, 114, 475-479.

38. Kushch, N.D.; Kazakova, A.V.; Dubrovskii, A.D.; Shilov, G.V.; Buravov, L.I.; Morgunov, R.B.; Kurganova, E.V.; Tanimoto, Y.; Yagubskii, E.B. Molecular magnetic semiconductors formed by cationic and anionic networks: $(\mathrm{ET})_{2} \mathrm{Mn}\left[\mathrm{N}(\mathrm{CN})_{2}\right]_{3}$ and $(\mathrm{ET})_{2} \mathrm{CuMn}\left[\mathrm{N}(\mathrm{CN})_{2}\right]_{4}$. J. Mater. Chem. 2007, 17, 4407-4413.

39. Narymbetov, B.Z.; Canadell, E.; Togonidze, T.; Khasanov, S.S.; Zorina, L.V.; Shibaeva, R.P.; Kobayashi, H. First-order phase transition in the organic metal $\kappa-(\mathrm{BETS})_{2}\left[\mathrm{C}(\mathrm{CN})_{3}\right]$. J. Mater. Chem. 2001, 11, 332-336.

40. Horiuchi, S.; Yamochi, H.; Saito, G.; Sakaguchi, K.; Kusunoki, M. Nature and origin of stable metallic state in organic charge-transfer complexes of bis(ethylenedioxy)tetrathiafulvalene. J. Am. Chem. Soc. 1996, 118, 8604-8622.

41. Sekizaki, S.; Konsha, A.; Yamochi, H.; Saito, G. Cation radical salts with flexible polycyano anions having tetracyanoallyl skeleton. Mol. Cryst. Liquid Cryst. 2002, 376, 207-212.

42. Yamochi, H.; Konsha, A.; Saito, G.; Matsumoto, K.; Kusunoki, M.; Sakaguchi, K. Molecular and crystal structures of 2-dicyanomethylene-1,1,3,4,5,5-Hexacyanopentenediide (DHCP) and its tetrathiafulvalene (TTF) complex. Mol. Cryst. Liquid Cryst. 2000, 350, 265-271.

43. Sekizaki, S.; Tada, C.; Yamochi, H.; Saito, G. Structural aspects of a series of cation radical salts of tetrathiotetracene (TTT) with 2-alkoxy-1,1,3,3-tetracyanoallyl anions (RO-TCA; R = Me, Et, Pr, Bu). J. Mater. Chem. 2001, 11, 2293-2302.

44. Benmansour, S.; Atmani, C.; Setifi, F.; Triki, S.; Marchivie, M.; Gómez-García, C.J. Polynitrile anions as ligands: From magnetic polymeric architectures to spin crossover materials. Coord. Chem. Rev. 2010, 254, 1468-1478.

45. Thétiot, F.; Triki, S.; Sala Pala, J.; Galán-Mascarós, J.; Martínez-Agudo, J.; Dunbar, K. Discrete dinuclear complexes and two-dimensional architectures from bridging polynitrile and bipyrimidine (bpym) ligands: Syntheses, structures and magnetic properties of $\left[\mathrm{M}_{2}(\mathrm{bpym})\right.$ $\left.(\text { dcne })_{4}\left(\mathrm{H}_{2} \mathrm{O}\right)_{2}\right] \quad\left(\mathrm{M}=\mathrm{Mn}^{\mathrm{II}}, \mathrm{Co}^{\mathrm{II}}\right)$ and $\left[\mathrm{M}_{2}(\mathrm{bpym})(\mathrm{dcne})_{4}\left(\mathrm{H}_{2} \mathrm{O}\right)_{4}\right] \cdot 2 \mathrm{H}_{2} \mathrm{O} \quad\left(\mathrm{M}=\mathrm{Fe}^{\mathrm{II}}, \mathrm{Cu}^{\mathrm{II}}\right)$ $\left.\left(\mathrm{dcne}^{-}=\left[(\mathrm{CN})_{2} \mathrm{CC}(\mathrm{O}) \mathrm{OEt}\right)\right]^{-}\right)$. Eur. J. Inorg. Chem. 2004, 2004, 3783-3791.

46. Thetiot, F.; Triki, S.; Pala, J.S.; Gómez-García, C.J. New coordination polymers with a 2,2-dicyano-1-ethoxyethenolate ( $\mathrm{dcne}^{-}$) bridging ligand: Syntheses, structural characterisation and magnetic properties of $\left[\mathrm{M}(\text { dene })_{2}\left(\mathrm{H}_{2} \mathrm{O}\right)_{2}\right]\left(\mathrm{M}=\mathrm{Mn}^{\mathrm{II}}, \mathrm{Fe}^{\mathrm{II}}, \mathrm{Co}^{\mathrm{II}}, \mathrm{Ni}^{\mathrm{II}}\right.$ and $\left.\mathrm{Zn}^{\mathrm{II}}\right)$ and $\left[\mathrm{Cu}(\mathrm{dcne})_{2}\left(\mathrm{H}_{2} \mathrm{O}\right)\right]$. J. Chem. Soc. Dalton Trans. 2002, doi:10.1039/B107944C.

47. Benmansour, S.; Setifi, F.; Triki, S.; Salaun, J.Y.; Vandevelde, F.; Sala-Pala, J.; Gómez-García, C.J.; Roisnel, T. New multidimensional coordination polymers with $\mu_{2}$ and $\mu_{3}$-dcno cyano carbanion ligand $\left\{\mathrm{dcno}^{-}=\left[(\mathrm{NC})_{2} \mathrm{CC}(\mathrm{O}) \mathrm{O}\left(\mathrm{CH}_{2}\right)_{2} \mathrm{OH}\right]^{-}\right\}$. Eur. J. Inorg. Chem. 2007, doi:10.1002/ejic.200600449. 
48. Triki, S.; Sala Pala, J.; Decoster, M.; Molinié, P.; Toupet, L. Novel infinite three-dimensional networks with highly conjugated polynitrile ligands: Syntheses, crystal structures, and magnetic properties of $\left[\mathrm{Cu}\left\{\mathrm{C}\left[\mathrm{C}(\mathrm{CN})_{2}\right]_{3}\right\}\left(\mathrm{H}_{2} \mathrm{O}\right)_{2}\right]_{n}$ and $\left[\mathrm{Cu}\left\{\mathrm{C}\left[\mathrm{C}(\mathrm{CN})_{2}\right]_{3}\right\}(\mathrm{en})\right]_{n}$ (en $\left.=\mathrm{NH}_{2} \mathrm{CH}_{2} \mathrm{CH}_{2} \mathrm{NH}_{2}\right)$. Angew. Chem. Int. Ed. 1999, 38, 113-115.

49. Benmansour, S.; Setifi, F.; Gómez-García, C.J.; Triki, S.; Coronado, E.; Salaun, J.Y. A novel polynitrile ligand with different coordination modes: Synthesis, structure and magnetic properties of the series $\left[\mathrm{M}(\mathrm{tcnoprOH})_{2}\left(\mathrm{H}_{2} \mathrm{O}\right)_{2}\right](\mathrm{M}=\mathrm{Mn}, \mathrm{Co}$ and $\mathrm{Cu})\left(\mathrm{tcnoprOH}{ }^{-}=\left[(\mathrm{NC})_{2} \mathrm{CC}\left(\mathrm{OCH}_{2} \mathrm{CH}_{2} \mathrm{CH}_{2} \mathrm{OH}\right)\right.\right.$ $\left.\left.\mathrm{C}(\mathrm{CN})_{2}\right]^{-}\right)$. J. Mol. Struct. 2008, 890, 255-262.

50. Benmansour, S.; Setifi, F.; Triki, S.; Gómez-García, C.J. Linkage Isomerism in Coordination Polymers. Inorg. Chem. 2012, 51, 2359-2365.

51. Atmani, C.; El Hajj, F.; Benmansour, S.; Marchivie, M.; Triki, S.; Conan, F.; Patinec, V.; Handel, H.; Dupouy, G.; Gómez-García, C.J. Guidelines to design new spin crossover materials. Coord. Chem. Rev. 2010, 254, 1559-1569.

52. Dupouy, G.; Marchivie, M.; Triki, S.; Sala-Pala, J.; Salaun, J.Y.; Gómez-García, C.J.; Guionneau, P. The key role of the intermolecular $\pi-\pi$ interactions in the presence of spin crossover in neutral $\left[\mathrm{Fe}(\mathrm{abpt})_{2} \mathrm{~A}_{2}\right]$ complexes $(\mathrm{A}=$ Terminal Monoanion $\mathrm{N}$ Ligand). Inorg. Chem. 2008, 47, 8921-8931.

53. Mori, T. Structural genealogy of BEDT-TTF-based organic conductors III. Twisted molecules: Delta and alpha' phases. Bull. Chem. Soc. Jpn. 1999, 72, 2011-2027.

54. Guionneau, P.; Kepert, C.J.; Bravic, G.; Chasseau, D.; Truter, M.R.; Kurmoo, M.; Day, P. Determining the charge distribution in BEDT-TTF salts. Synth. Met. 1997, 86, 1973-1974.

55. Dupouy, G.; Triki, S.; Marchivie, M.; Cosquer, N.; Gómez-García, C.J.; Pillet, S.; Bendeif, E.-E.; Lecomte, C.; Asthana, S.; Létard, J.-F. Cyanocarbanion-based spin-crossover materials: Photocrystallographic and photomagnetic studies of a new iron(II) neutral chain. Inorg. Chem. 2010, 49, 9358-9368.

56. Mori, T.; Mori, H.; Tanaka, S. Structural genealogy of BEDT-TTF-based organic conductors-II. Inclined molecules: Theta, alpha, and chi phases. Bull. Chem. Soc. Jpn. 1999, 72, 179-197.

57. Mori, T. Structural genealogy of BEDT-TTF-based organic conductors I. Parallel molecules: Beta and beta" phases. Bull. Chem. Soc. Jpn. 1998, 71, 2509-2526.

58. Triki, S.; Thetiot, F.; Vandevelde, F.; Sala-Pala, J.; Gómez-García, C.J. New magnetic copper(II) coordination polymers with the polynitrile ligand $\left(\mathrm{C}\left[\mathrm{C}(\mathrm{CN})_{2}\right]_{3}\right)^{2-}$ ) and N-Donor Co-Ligands. Inorg. Chem. 2005, 44, 4086-4093.

59. Benmansour, S.; Setifi, F.; Gómez-García, C.J.; Triki, S.; Coronado, E. New coordination polymers based on a novel polynitrile ligand: Synthesis, structure and magnetic properties of the series $\left[\mathrm{M}(\text { tcnoetOH })_{2}\left(4,4^{\prime}\right.\right.$-bpy $\left.)\left(\mathrm{H}_{2} \mathrm{O}\right)_{2}\right]\left(\right.$ tcnoetOH $^{-}=\left[(\mathrm{NC})_{2} \mathrm{CC}\left(\mathrm{OCH}_{2} \mathrm{CH}_{2} \mathrm{OH}\right) \mathrm{C}(\mathrm{CN})_{2}\right]^{-} ; \mathrm{M}=\mathrm{Fe}$, Co and Ni). Inorg. Chim. Acta 2008, 361, 3856-3862.

60. PROCESS; Rigaku Corporation: Tokyo, Japan, 1996.

61. Xcalibur CCD/RED System; Oxford Diffraction: Abingdon, UK, 2006.

62. Altomare, A.; Burla, M.C.; Camalli, M.; Cascarano, G.L.; Giacovazzo, C.; Guagliardi, A.; Moliterni, A.G.G.; Polidori, G.; Spagna, R. SIR97: A New tool for crystal structure determination and refinement. J. Appl. Cryst. 1999, 32, 115-119.

63. Sheldrick, G.M. A short history of SHELX. Acta Crystallogr. Sect. A 2008, 64, 112-122. 
64. Farrugia, L.J. WinGX suite for small-molecule single-crystal crystallography. J. Appl. Cryst. 1999, 32, 837-838.

65. Dolomanov, O.V.; Bourhis, L.J.; Gildea, R.J.; Howard, J.A.K.; Puschmann, H. OLEX2: A complete structure solution, refinement and analysis program. J. Appl. Cryst. 2009, 42, 339-341.

66. CCDC CIF Depository Request Form for data published from 1994. Available online: http://www.ccdc.cam.ac.uk/data_request/cif (accessed on 19 April 2012).

(C) 2012 by the authors; licensee MDPI, Basel, Switzerland. This article is an open access article distributed under the terms and conditions of the Creative Commons Attribution license (http://creativecommons.org/licenses/by/3.0/). 